R. Sergio Balches Arenas

Uniwersytet Jagielloński w Krakowie sergio.balches@uj.edu.pl

\title{
Situación de los docentes de español /LE en centros de enseñanza secundaria en Cracovia: aproximación a un análisis de expectativas y satisfacción profesional
}

\section{Resumen:}

El objetivo del presente trabajo se centra en ofrecer un análisis sincrónico de corte empírico sobre la percepción que el profesorado de centros de Enseñanza Secundaria ubicados en el área metropolitana de Cracovia tienen sobre el trabajo que realizan y sobre el alumnado con el que desarrollan su labor docente. A través de dicha encuesta podremos observar las valoraciones que los mismos llevan a cabo sobre aspectos tales como el ambiente de trabajo, el centro escolar, su salario, las fortalezas y debilidades de los centros educativos, etc. Todo ello irá precedido de una aproximación al sistema educativo polaco que nos ofrecerá una referencia previa en torno a la realidad en la que se desenvuelve este estudio.

Palabras clave: sistema educativo, evaluación, expectativas y satisfacción profesional, profesorado. 


\section{Abstract: \\ The Situation of Secondary School Spanish Teachers in Cracow: an Analisis of Their Expectations and Their Job Satisfaction}

The goal of this paper is to offer -from a synchronic perspective- an empirical analysis of the way Secondary School teachers within the Cracow metropolitan area perceive their teaching and the students they work with. Thanks to the conducted survey we will be able to observe the evaluation of aspects such as work environment and atmosphere, the teaching institution, salary, the strengths and weaknesses of educational centres, etc. This will be preceded by a brief study into the Polish education system which will provide an introductory reference to the context the research was carried out in. Keywords: education system, evaluation, job satisfaction and expectations, teachers.

\section{Introducción}

Uno de los pilares básicos en cualquier sistema educativo es el profesorado, razón por la cual deseamos realizar una aproximación, a través del análisis de diversos parámetros, a la situación en la que se encuentran los profesores que imparten español /LE en centros educativos de la zona metropolitana de Cracovia. Hay que partir de la base de que este análisis se inscribe en una muy somera evaluación en el ámbito educativo, dado que no es nuestra pretensión abarcar las grandes cifras macroestadísticas que atañen al sistema educativo polaco, sino que, simplemente, pretendemos ofrecer una visión en un corte sincrónico concreto de la valoración que hace el profesorado de enseñanza secundaria de español /LE del área metropolitana de Cracovia de su trabajo.

Así pues, a través de la realización de una serie de encuestas a estos docentes, las cuales se llevaron a cabo durante al curso académico 2009/2010, se intenta por medio del presente artículo ofrecer una visión empírica que recoja las apreciaciones que estos profesionales de la enseñanza manifestaron en su día acerca de sus motivaciones y expectativas profesionales, además de la percepción de los aspectos 
positivos y negativos que poseían acerca del desempeño de la función docente en el momento de realizarse dichas encuestas.

El hecho de que no hayan sido analizadas estas encuestas hasta la fecha, se explica mediante diversos factores, aunque el principal consistía en no poder contar con una sólida documentación que analizara diversos sistemas educativos, entre ellos el sistema polaco, y que ofreciera unos datos que pudieran parangonarse sincrónicamente con los datos obtenidos en el estudio empírico que ahora presentamos. Así, encontramos, por ejemplo, que los últimos estándares internacionales de clasificación de la educación de la UNESCO son de 2011, mientras que el último informe PISA, que corresponde a 2009, vio la luz en 2010, cuando fue presentado por el Ministerio de Educación Nacional.

En cuanto al trabajo que a continuación se desarrolla, pretendemos comenzar con una breve descripción del sistema educativo polaco para, a continuación, aproximarnos a la figura del profesor de enseñanza secundaria en Polonia desde la perspectiva de su carrera profesional. Posteriormente, pasaremos a hablar de la metodología aplicada a la presente encuesta, a fin de clarificar el proceso de análisis de los resultados de la misma, estableciendo para ello una breve descripción del perfil de los encuestados, pasando por una aproximación al entorno educativo en el área metropolitana de Cracovia y terminando con los criterios de valoración de la encuesta en cuestión. Tras todo ello, continuaremos con el cuerpo central del artículo que nos ocupa, esto es, el análisis de las encuestas y la valoración de los resultados. Para finalizar, expondremos unas breves conclusiones a tenor de lo señalado en las encuestas ${ }^{1}$.

${ }^{1}$ Antes de finalizar la presente introducción, no queremos dejar pasar la ocasión de señalar que, para la realización las encuestas, contamos en su día con la inestimable colaboración de los alumnos de la materia Metodología de la enseñanza del español /LE de la promoción 2009/2010, impartida en $5^{\circ}$ curso de Filología Hispánica en la Universidad Jaguelónica de Cracovia, los cuales participaron de forma activa a la hora de traducir al polaco el contenido de los formularios y de desplazarse a los diversos centros educativos para recoger las 


\section{Breve descripción del sistema educativo polaco y competencia profesional del docente en Polonia}

\subsection{Aproximación al sistema educativo polaco}

Según la información publicada por el anuario El mundo estudia español 2009-2010 [MECD y Universidad de Valencia, on-line], el sistema educativo polaco se organiza en diversas escalas jerárquicas competenciales, hallándose en el nivel más elevado el Ministerio de Educación Nacional (en adelante, MEN), que regula la política educativa en el plano estatal. Con posterioridad, tienen competencias en el ámbito educativo las administraciones regionales, al frente de las cuales se halla un inspector de educación (kurator), que dirige la inspección educativa en cada región (kuratorium oświaty). Más abajo en la escala de competencias, nos encontraremos el distrito (powiat) $\mathrm{y}$, finalmente, con la comuna (gmina), que se halla en el plano de la administración local.

En el ámbito que nos ocupa, la administración de las comunas conjuntamente con el MEN son las administraciones que se encargan de la gestión de los centros de enseñanza secundaria obligatoria, mientras que es la administración del distrito, también conjuntamente con el MEN, la responsable de la gestión de los centros de educación secundaria superior. También la administración de las comunas es la encargada de la educación infantil, así como de la educación primaria.

Teniendo en cuenta la descripción general que del sistema educativo realiza Joanna Jung-Miklaszewska [on-line], podemos resaltar que tras la aprobación de la reforma educativa de 1999² [MEN, 1998: 4320-4328], la cual actualmente está en vigor, el sistema educativo polaco sufrió un cambio en el ámbito de la educación no universitaria, pasando la educación primaria a tener una duración de 6 años,

encuestas rellenadas. A ellos, encarecidamente, deseamos transmitirles desde estas líneas nuestro más sincero agradecimiento y reconocimiento.

2 Articulada a través de la Ley de 25 de julio de 1998, de modificación de la ley sobre el sistema educativo. 
comenzando desde los 7 años hasta los 13 años de edad, divididos en dos ciclos de 3 años cada uno. En cuanto a la educación secundaria, se dividió en dos modalidades diferenciadas: por un lado, la educación secundaria obligatoria, de nueva aparición y con una duración de 3 años, que comprende a los alumnos desde los 13 hasta los 16 años de edad; por otro, la educación secundaria superior, con una duración variable de 3 a 4 años, dependiendo del tipo de estudios y centro en el que curse sus estudios el alumno, desde los 16 a los 18 (o 19) años de edad.

En cuanto a la educación secundaria superior, existen diversos itinerarios formativos, dado que los estudiantes pueden optar, bien por la realización de estudios generales (equivalentes al bachillerato en España) y que son conducentes a la realización de un examen de reválida (en polaco, matura), bien por la realización de estudios de formación profesional, desde los cuales se puede pasar, bien a unos estudios avanzados de formación profesional, bien a unos estudios complementarios de enseñanza general, a fin de poder realizar dicho examen de reválida.

Descriptivamente, el sistema educativo polaco para la enseñanza no universitaria, puede esquematizarse de la siguiente forma: 
R. Sergio Balches Arenas

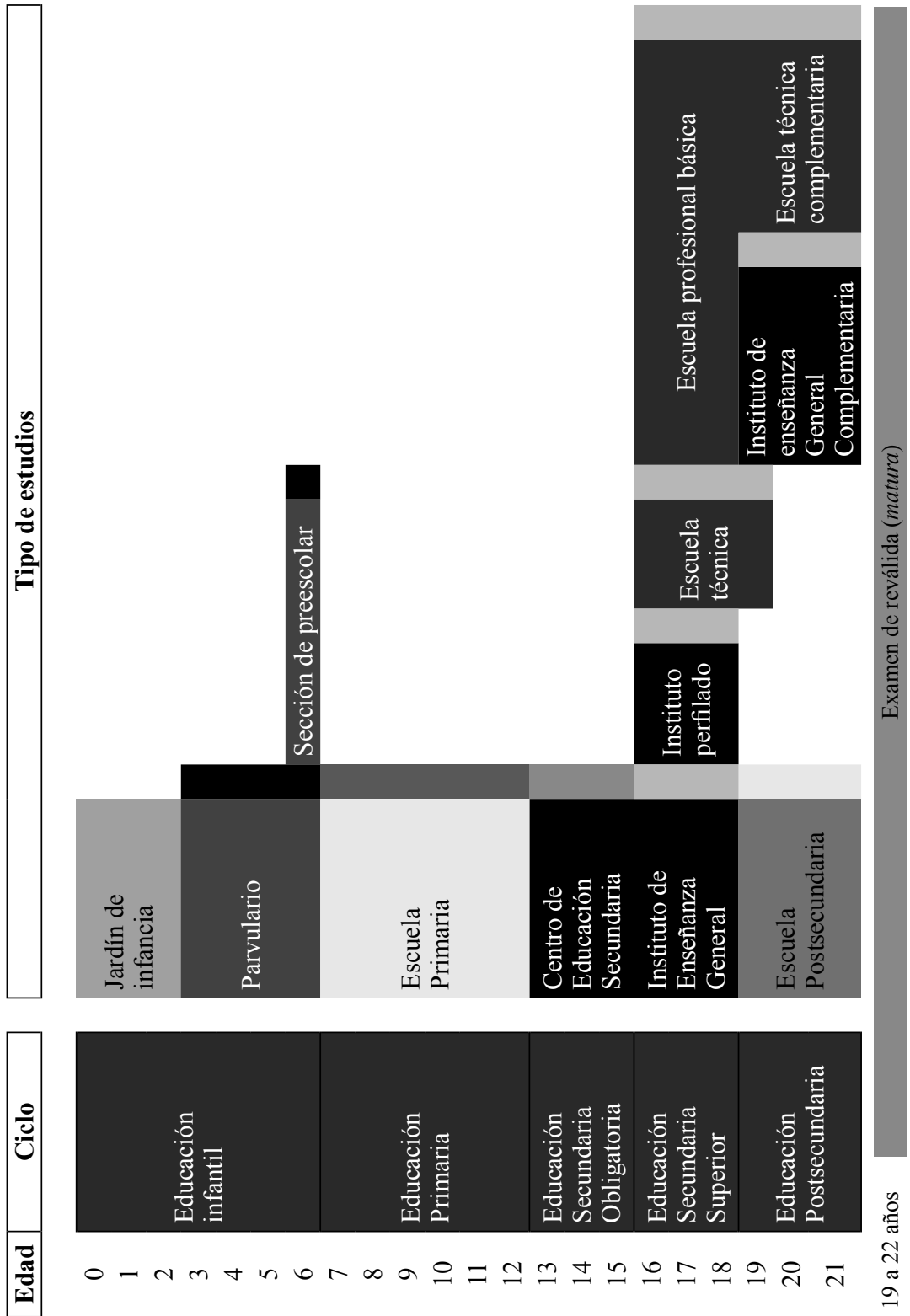




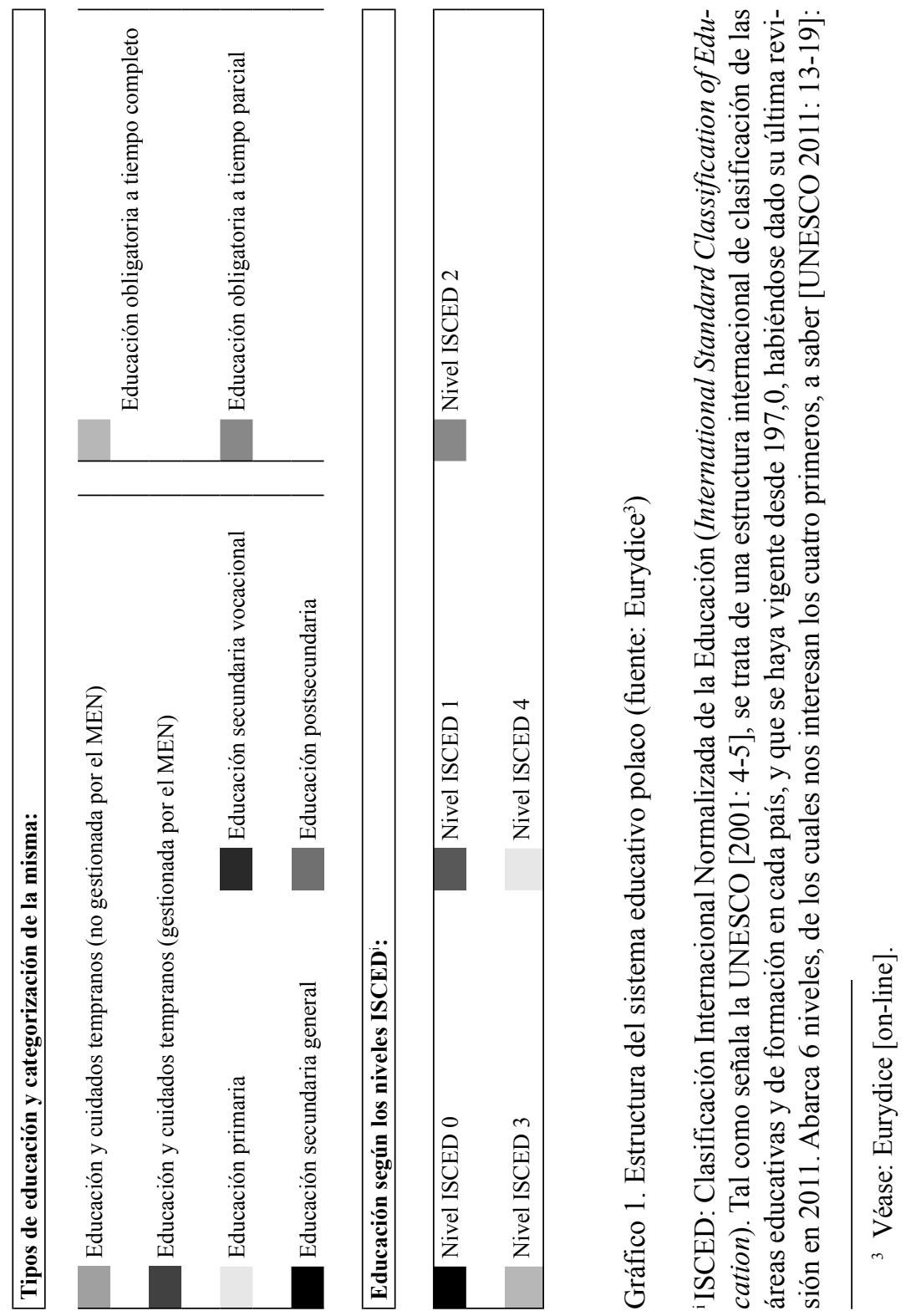


- NIVEL 0: se refiere a la educación en la etapa preescolar.

- NIVEL 1: se refiere a la educación primaria o al primer ciclo de educación básica.

- NIVEL 2: se refiere a la educación en el primer ciclo de educación secundaria o al segundo ciclo de la educación básica.

- NIVEL 3: se refiere a la educación secundaria.

- NIVEL 4: se refiere a la educación secundaria avanzada o educación postsecundaria no superior.

Para finalizar este capítulo, se ha de indicar que la reforma educativa de 1999 suscitó numerosas críticas, las cuales perduran en mayor o menor medida hasta el día de hoy. No obstante, se han de tener en cuenta los indicadores de los informes PISA correspondientes a los años 2000, 2003, 2006 y 2009. En este caso, hemos seleccionado los resultados correspondientes a la prueba de lectura e interpretación, dado que entendemos que es la más afecta a la enseñanza de lengua materna y lenguas extranjeras. Dichos resultados otorgaban al sistema educativo polaco las posiciones que veremos en el gráfico $2^{4}$, contrastadas con los cinco primeros sistemas educativos de cada uno de los años evaluados por dichos informes:

\begin{tabular}{|c|c|c|c|c|c|c|c|c|c|c|c|}
\hline & \multicolumn{2}{|c|}{ Año 2000} & \multicolumn{3}{|c|}{ Año 2003} & \multicolumn{3}{|c|}{ Año 2006} & \multicolumn{3}{|c|}{ Año 2009} \\
\hline 1 & $\begin{array}{l}\text { Fin- } \\
\text { landia }\end{array}$ & 546 & 1 & $\begin{array}{c}\text { Finlan- } \\
\text { dia }\end{array}$ & 543 & 1 & $\begin{array}{c}\text { Corea } \\
\text { Sur }\end{array}$ & 556 & 1 & $\begin{array}{l}\text { Shan- } \\
\text { gai }\end{array}$ & 556 \\
\hline 2 & Canadá & 534 & 2 & $\begin{array}{c}\text { Corea } \\
\text { Sur }\end{array}$ & 534 & 2 & $\begin{array}{l}\text { Fin- } \\
\text { landia }\end{array}$ & 547 & 2 & $\begin{array}{c}\text { Corea } \\
\text { Sur }\end{array}$ & 539 \\
\hline 3 & $\begin{array}{c}\text { Nueva } \\
\text { Zel. }\end{array}$ & 529 & 3 & Canadá & 528 & 3 & $\begin{array}{l}\text { Hong- } \\
\text { Kong }\end{array}$ & 536 & 3 & $\begin{array}{l}\text { Fin- } \\
\text { landia }\end{array}$ & 536 \\
\hline 4 & $\begin{array}{l}\text { Aus- } \\
\text { tralia }\end{array}$ & 528 & 4 & $\begin{array}{c}\text { Austra- } \\
\text { lia }\end{array}$ & 525 & 4 & Canadá & 527 & 4 & $\begin{array}{l}\text { Hong- } \\
\text { Kong }\end{array}$ & 533 \\
\hline
\end{tabular}

${ }^{4}$ Información extraída de Wikipedia, bajo el epígrafe "PISA (badanie)" [on-line]. 


\begin{tabular}{|lll|ccc|ccc|ccc|}
\multicolumn{2}{|c|}{ Año 2000 } & \multicolumn{3}{|c|}{ Año 2003 } & \multicolumn{3}{|c|}{ Año 2006 } & \multicolumn{3}{c|}{ Año 2009 } \\
5 & Irlanda & 527 & 5 & $\begin{array}{c}\text { Lie- } \\
\text { chtens- } \\
\text { tein }\end{array}$ & 525 & 5 & $\begin{array}{c}\text { Nueva } \\
\text { Zel. }\end{array}$ & 521 & 5 & $\begin{array}{c}\text { Singa- } \\
\text { pur }\end{array}$ & 526 \\
24 & Polonia & 479 & 16 & Polonia & 497 & 9 & Polonia & 508 & 15 & Polonia & 500 \\
\hline
\end{tabular}

Gráfico 2. Resultados de la prueba de lectura e interpretación de los informes PISA (fuente: Wikipedia)

De lo cual podemos inferir que, si bien Polonia ya se hallaba entre los 30 primeros países justo en el inicio de la aplicación de la reforma educativa, concretamente en el año 2000, se dio con posterioridad una subida de 8 puestos en la clasificación general al finalizar los estudios de educación secundaria obligatoria la primera promoción resultante del nuevo sistema educativo, tal como se puede apreciar en los resultados de 2003. Dicha subida se vería incrementada en el informe de 2006 en 7 puestos, al pasar al lugar número 9 de la clasificación general, aunque en el informe de 2009 baja al puesto 15, perdiendo 6 puntos, tal como podemos observar en el gráfico anterior.

Con todo, habrá que estar pendientes de los resultados del informe PISA correspondiente a 2012, a fin de ver si se mantiene la tendencia a la bajada en la clasificación o, por el contrario, la situación de 2009 ha sido únicamente una fluctuación negativa con perspectivas de recuperación.

\subsection{Aproximación al perfil del profesorado de enseñanza secundaria en Polonia}

En cuanto al profesorado que puede impartir clase en centros de enseñanza secundaria, es contratado directamente por el director del centro educativo, que es quien tiene la potestad, entre otras, de realizar los contratos que estime oportunos para garantizar la docencia en el 
centro del que se encarga ${ }^{5}$. Dicho profesorado se halla distribuido en diversas categorías académicas, a las que puede ir accediendo por medio de entrevistas, exámenes y por concurso de méritos.

La carrera académica de un docente en la enseñanza secundaria polaca está regulada por la siguiente normativa ${ }^{6}$ : la Orden del Ministro de Educación Nacional de 1 de diciembre de 2004, sobre la obtención de los grados de promoción del profesorado, la Orden del Ministro de Educación Nacional de 14 de noviembre de 2007, modificadora de la orden ministerial sobre la obtención de los grados de promoción del profesorado, así como también por la Proclamación del Presidente de la Dieta de la República Polaca de 17 de mayo de 2006, sobre la promulgación del texto refundido de la Ley de la Carta del Profesor ${ }^{7}$. En estos textos legislativos se indican las condiciones necesarias para que un docente vaya obteniendo las pertinentes promociones a grados superiores, la documentación necesaria que éste debe preparar en cada caso y señalan quiénes juzgarán los distintos aspectos relacionados con cada tipo de promoción profesional. En referencia a esta cuestión, parece pertinente abordar a grandes rasgos las fases por las que pasa un profesor desde el comienzo de su carrera académica hasta alcanzar el máximo grado en la misma, dado que nos permitirá tener una adecuada percepción sobre el desarrollo de la competencia profesional de los docentes de enseñanza secundaria. De esta manera, las fases a las que hemos hecho referencia pueden seguirse a través del siguiente gráfico [MEN, 2004: 18339-18344, Marszałek Sejmu, 2006: 26-35]:

5 Según el anuario El mundo estudia español 2009-2010 [MECD y Universidad de Valencia, on-line: 354$]$, los directores tienen otras atribuciones, además de contratar al profesorado, que consisten en "contratar al personal no docente, tienen atribuciones para otorgar algunos complementos salariales, determinar las normas de disciplina y las sanciones, supervisar la labor didáctica del profesorado, proponer condecoraciones, etc."

6 Traducciones realizadas por el autor del artículo.

7 En adelante, Carta del Profesor. 


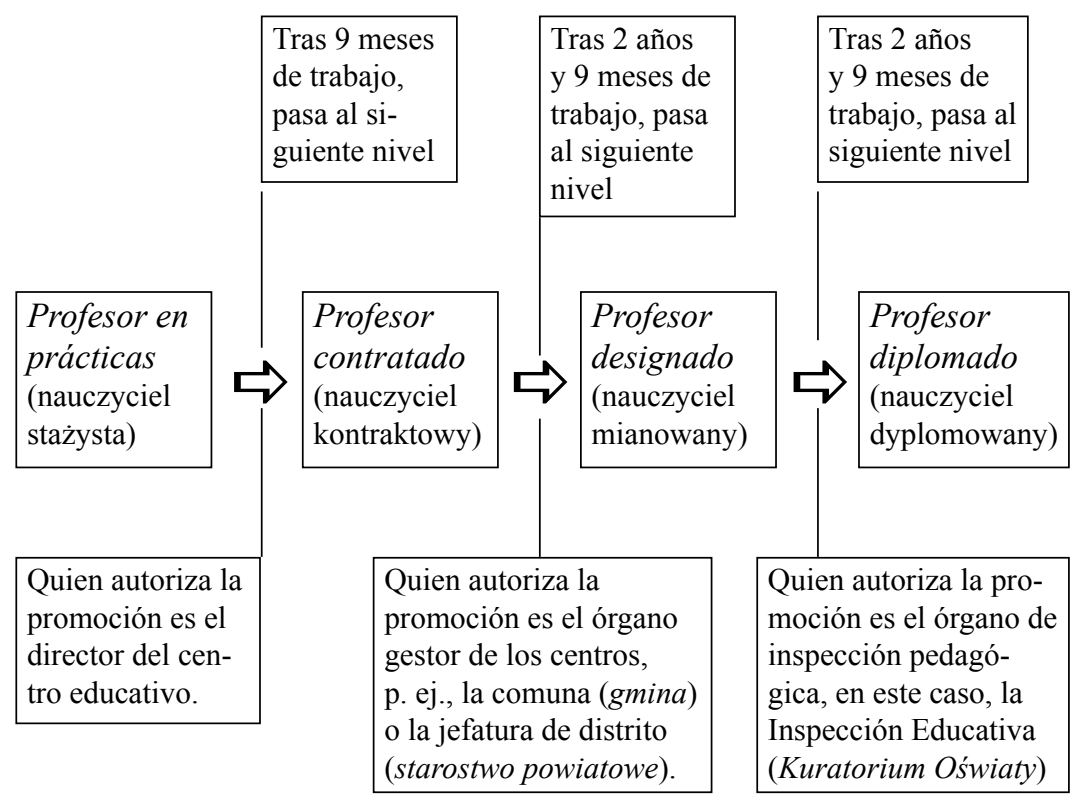

Gráfico 3. Trayectoria profesional del profesorado de enseñanza secundaria en Polonia

Como ya ha sido dicho, tanto en la orden del MEN de 2004 [18339-18344], así como en la modificación a la misma realizada en 2007 [15484-15486], se señalan todos los trámites administrativos y burocráticos que el docente debe llevar a cabo para promocionarse, el tipo de prueba que debe realizar y la composición de las comisiones evaluadoras.

En cuanto a la evaluación, que debe orientarse hacia el hecho de incrementar la eficacia didáctica del profesor, así como la calidad del trabajo académico que realiza, se prevé en el artículo 6a de la Carta del Profesor [Marszałek Sejmu, 2006: 23-24] que todos los docentes, excepto los profesores en prácticas, deberán someterse al proceso evaluatorio, a fin de garantizar los requisitos de calidad docente que se exigen por parte del MEN a los enseñantes. Dicha evaluación puede ser solicitada por el propio profesor, por el órgano al que corres- 
ponde la gestión del centro, por el órgano director del centro escolar, por la junta escolar o por el consejo de padres.

La evaluación del profesor es realizada por el director del centro en el que el profesor evaluado está contratado, aunque se da el caso de que si dicho director no tuviera las competencias pedagógicas correspondientes, puede llevar a cabo este procedimiento con el apoyo de un profesor del centro que posea la capacidad de control pedagógico en el mismo.

La evaluación de la calidad del trabajo escolar del docente se lleva a cabo en función a los parámetros establecidos por la Carta del Profesor, atendiendo al hecho de que el profesor cumpla con las tareas y obligaciones señaladas en este texto legal. Dichos parámetros son aplicados por el director del centro escolar, el cual se remite al articulado anteriormente señalado de este texto legislativo, que señala, entre otros, los siguientes aspectos:

- Cómo el profesor cumple las tareas escolares previstas en el estatuto de la escuela en la que está contratado, si despierta el interés por la materia entre sus alumnos y mantiene disciplina durante las clases, y si utiliza un lenguaje adecuado en el contacto con los alumnos.

- Si el profesor participa de una manera activa en el proceso de enseñanza, es decir, si organiza las actividades para los alumnos después de las clases, si participa en diferentes proyectos realizados por otros profesores en el centro escolar, si se interesa por los alumnos y su educación o si coopera con los padres de los alumnos.

- $\quad$ Si el profesor se desarrolla profesionalmente, si sabe responder a diferentes expectativas y necesidades de los alumnos, si sigue las normas del trabajo, es decir, si llega a las clases puntualmente y si aprovecha el total tiempo de la clase para enseñar [Marszałek Sejmu, 2006: 23-24].

Por último, cabe señalar que la puntuación obtenida en esta evaluación puede englobarse en tres categorías: a) Excelente (de 29 a 44 puntos), b) Buena (de 18 a 28 puntos) y c) Negativa (de 0 a 17 pun- 
tos). Se ha de indicar que, en el caso de obtener una evaluación negativa, el profesor cesará en sus obligaciones contractuales con el centro en el que presta sus servicios, tal como dispone el articulado al que hemos hecho referencia con anterioridad.

\section{Metodología de la encuesta}

En primer lugar, tal como fue expuesto en la introducción, elaboramos la encuesta en lengua española y gracias a los estudiantes de la especialidad pedagógica de la titulación de Filología Hispánica (promoción 2009/2010) se pudo traducir al polaco, a fin de que fuera más fácil responder a los encuestados. Además, dichos estudiantes prestaron un importante servicio a la hora de desplazarse en persona a los centros de enseñanza secundaria que no habían remitido las respuestas a la encuesta por correo electrónico para recoger los impresos cumplimentados.

La encuesta ${ }^{8}$ se realizó en el periodo comprendido entre diciembre de 2009 y mayo de 2010, dirigiéndose a los docentes pertenecientes a centros de educación secundaria del área metropolitana de Cracovia. Constaba de dos partes bien diferenciadas: la primera estaba encaminada a analizar el centro educativo y a sus estudiantes, mientras que la segunda parte se encaminaba al análisis de la figura del docente y de su grado de satisfacción en el trabajo.

\subsection{Descripción de la encuesta y de los sujetos de estudio}

Como se podrá apreciar, en este trabajo abordamos únicamente el estudio de la segunda parte de la encuesta realizada: analizar la situación del docente de enseñanza secundaria en el área metropolitana de Cracovia, así como su grado de satisfacción en el ámbito laboral.

${ }^{8}$ Véase el anexo I del presente artículo. 


\subsubsection{La encuesta}

En relación con la encuesta, consta de una introducción acerca de la filiación personal y laboral del docente, seguida de preguntas acerca de la titulación cursada, del contacto mantenido con la lengua española, del tiempo dedicado a la enseñanza, del importe del salario mensual percibido, del grado de felicidad en el trabajo, de los aspectos que el encuestado cambiaría en su trabajo y de los problemas principales con que se enfrenta en el trabajo. Además, se incluyen tres cuestiones más, destinadas a valorar la acción del alumnado, a saber: sobre el interés de los estudiantes en la lengua española, sobre la participación de los mismos en las clases y sobre las motivaciones de dichos estudiantes a la hora de iniciar los estudios de español /LE en su centro de enseñanza.

\subsubsection{La muestra}

Al respecto de los sujetos de estudio seleccionados para realizar la encuesta, la idea principal era dirigirse a docentes de enseñanza secundaria, tanto obligatoria como superior, que realizaran su actividad laboral en centros educativos del área metropolitana de Cracovia. Para ello, se siguió el siguiente procedimiento: en primer lugar, nos pusimos en contacto con la Inspección Educativa de Cracovia, a fin de recabar un listado de centros de enseñanza secundaria que ofertaran la enseñanza de español /LE, así como una lista de profesores de español /LE en activo. La respuesta de dicha Inspección Educativa se hizo esperar, suministrando únicamente una breve lista de centros que impartían español /LE, que ascendía a 16 centros (de los cuales uno de ellos era una escuela primaria), pero no así la lista de profesorado que se le había demandado.

A través de dicha lista se procedió a realizar una investigación en las respectivas páginas de Internet de los centros reseñados en la misma, así como a contactar con colegas que estaban llevando a cabo su actividad docente durante el curso académico 2009/2010 en educación secundaria, con lo que pudimos ampliar los criterios de búsque- 
da, llegando a detectar que existían 23 centros de secundaria, tanto obligatoria como superior, que impartían en sus aulas clases de español /LE, aunque en algunos casos, la presencia de esta lengua era casi residual en algunos de los centros investigados.

Como resultado de esta búsqueda ulterior, encontramos que, dependiendo del centro, la plantilla variaba desde un solo profesor (en la mayoría de los casos) hasta 5 profesores (en uno solo de los casos), con lo que nos encontrábamos ante un número potencial de docentes que llegaba hasta los 27 profesores en activo, teniendo en cuenta que algunos de ellos trabajaban en más de un centro educativo, lo cual es una situación usual en el ámbito de la educación polaca en todos sus niveles. Así pues, a través de diversos medios nos pusimos en contacto con dichos profesores para remitirles la encuesta en cuestión a fin de que la contestaran y nos fuera devuelta para procesar los datos correspondientes a la misma.

De los 27 sujetos de estudio potenciales, sólo respondieron a la encuesta 18, de los cuales 17 de ellos trabajaban en centros de enseñanza secundaria y 1 en un centro de enseñanza primaria. En cuanto al resto del profesorado (8 sujetos), bien no obtuvimos respuesta alguna por parte de algunos de esos docentes, bien algunos otros contestaron que no rellenarían la encuesta porque incluía preguntas que les afectaban de una forma directa y personal y no querían tener posteriores problemas con su centro de trabajo, lo cual obviamente respetamos.

\subsection{Criterios de valoración de los resultados}

\subsubsection{Validación de los datos y edición de los mismos}

Acerca de los criterios que hemos seguido para la valoración de los resultados, hemos de indicar que, en términos generales, 18 sujetos respondieron a la encuesta, tal como ya hemos indicado con anterioridad, aunque se da la circunstancia de que 1 de esos sujetos trabajaba en un centro de educación primaria y 3 de los demás docentes encuestados trabajaban en dos centros educativos distintos simultáneamente. 
En función a las situaciones descritas, hemos decidido admitir la encuesta realizada por el docente que trabaja en educación primaria como válida y también hemos adoptado el criterio de analizar independientemente las encuestas de los 3 docentes que trabajan en más de un centro educativo, al comprobar en sus respuestas que existen algunas diferencias según se trate de un centro de trabajo o de otro, lo cual nos indica que no han llevado a cabo una automatización o duplicación de sus respuestas en ambas encuestas. Por todo ello, tomamos el criterio de elevar el total de encuestas válidas para computar los resultados de 17 a 21 . Esto nos conduce a que cada encuesta será tratada separadamente y asumiremos que estamos analizando a 21 encuestados distintos.

Una vez establecidos los criterios de validación de las encuestas, se procedió a la tabulación de los datos contenidos en las mismas y su informatización, a fin de poder agruparlos en función a los ítemes que la encuesta reflejaba, teniéndose que realizar diversas operaciones para trabajar con dichos datos. La primera de ella consistió en la traducción del polaco al español de las respuestas dadas por los docentes, puesto que incluso las personas nativas hispanohablantes contestaron en lengua polaca.

Posteriormente hubo que establecer unos criterios unificadores al respecto de las respuestas libres recogidas en algunos apartados de la encuesta, con el objetivo de estandarizar las respuestas dadas, de tal forma que se pudieran agrupar en factores computables, por lo que se atendió a la idea general que cada informante quería expresar para cada uno de los aspectos que permitían una opinión libre, agrupando las respuestas en distintos campos, tal como se podrá ver en el análisis de los resultados.

Finalmente, tras la uniformización de ideas en las respuestas libres, se procedió a realizar un estudio estadístico, tanto de dichas respuestas como de las respuestas de selección múltiple que se encontraban en la encuesta, pasando con posterioridad al correspondiente análisis de resultados. 


\subsubsection{Aspectos relevantes de la investigación realizada}

Nuestra intención inicial era centrarnos en estudiar qué apreciaciones tenía el profesorado de enseñanza secundaria al respecto de su figura como docente y de aquellos aspectos que consideraba relevantes sobre el centro donde trabajaba, dado que el entorno laboral era un importante factor a tener en cuenta de cara a valorar su satisfacción general, pues entendíamos que el ambiente de trabajo influye en las condiciones laborales académica y administrativamente. Junto a esta premisa de partida, también consideramos que era necesario establecer un elemento de juicio más: el papel que los alumnos tenían en relación con su trabajo.

Así pues, percibimos que era conveniente añadir tres apartados más, dado que con ello podía apreciarse que el contacto directo con los receptores de esta actividad profesional influye, en mayor o menor medida, en el grado total de satisfacción obtenido por los docentes, puesto que su acción formativa se focaliza y concretiza en los sujetos de dicha formación, es decir, en sus estudiantes. Ello, como hemos señalado, se convierte en un elemento más que se ha de evaluar para obtener una perspectiva global en cuanto a la satisfacción profesional (y eventualmente personal) del profesorado.

Con todo este bagaje, hemos intentado realizar una aproximación lo más certera posible a las percepciones y valoraciones que posee el profesorado de enseñanza secundaria en el área metropolitana de Cracovia, atendiendo a varios ejes de estudio principales, tratados pormenorizadamente en el análisis de los resultados de las encuestas, teniendo en cuenta los criterios de rigurosidad, claridad y validez, sin los cuales, consideramos que el trabajo empírico llevado a cabo adolecería del carácter científico que lo anima. 


\section{Análisis de los resultados de la encuesta}

\subsection{Caracterización del perfil de los encuestados}

En primer lugar, se hace preciso caracterizar a los sujetos que han participado en la presente encuesta. Tal como señalamos en el capítulo anterior, tenemos 19 personas encuestadas, de las cuales, 2 de ellas han cumplimentado dos encuestas debido a que trabajan en dos centros educativos distintos. Ateniéndonos a la metodología expuesta, trabajaremos con un total de 21 encuestas, dado que, a pesar de que en esos dos casos señalados los encuestados son las mismas personas, posteriormente las respuestas en distintos apartados de esta encuesta varían según el centro escolar del que se trate.

En cuanto al sexo, las mujeres constituyen la mayoría de los docentes que han cumplimentado el cuestionario, ascendiendo a un total de 16, frente a los hombres, los cuales ascienden a 5 encuestados:

Distribución de los encuestados por sexo

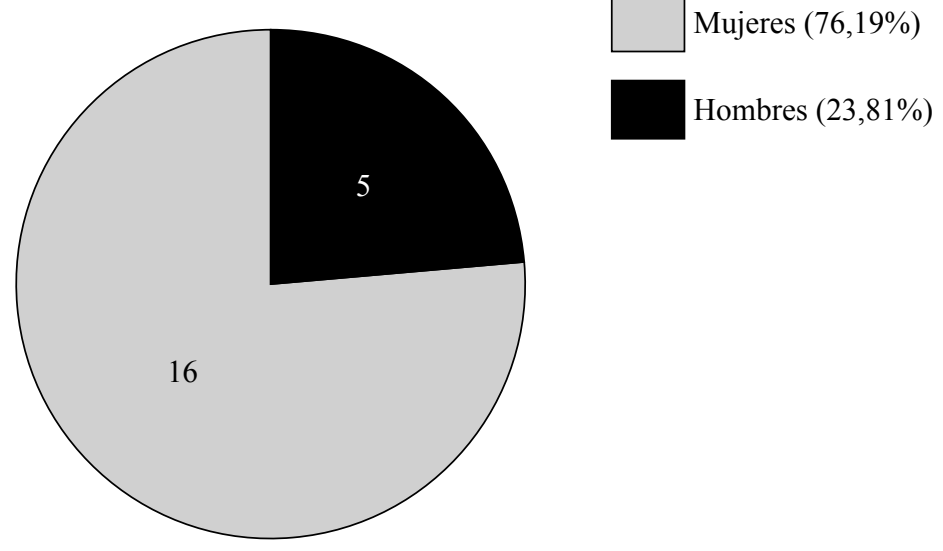

También se ha de indicar que la mayoría de estos docentes (11) trabaja en un centro de enseñanza secundaria público, cifra a la que debemos añadir 1 docente más, que trabaja en un centro de enseñanza 
primaria también público. El resto de docentes (9) declaran trabajar en un centro de enseñanza secundaria privado.

Por sexos, de los docentes que trabajan en centros públicos, 2 son hombres y 10 son mujeres (incluida en este grupo la docente que trabaja en el centro de enseñanza primaria al que hemos hecho referencia con anterioridad), mientras que con respecto a los docentes que trabajan en centros privados, 3 de ellos son hombres y 6 son mujeres. Veamos su distribución porcentual en el siguiente gráfico:

Distribución de los encuestados por tipo de centro y sexo

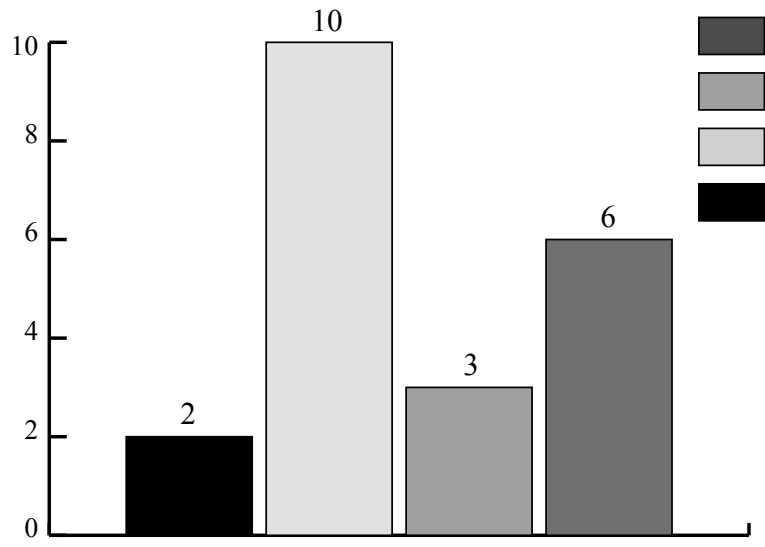

Cent. Priv. M (28,57\%)

Cent. Priv. H $(14,28 \%)$

Cent. Públ. M (47,61\%)

Cent. Públ. H $(9,52 \%)$

Otro aspecto que hemos recogido en esta encuesta, destinado a caracterizar el perfil de los docentes del área metropolitana de Cracovia, ha sido el tiempo que llevan desarrollando su labor profesional, hecho que nos ha parecido un dato pertinente en orden a valorar el grado de experiencia docente que poseen los informantes. Así pues, podemos señalar que la media global de años dedicados a la enseñanza es de 7,6 años, poseyendo el docente que más tiempo lleva trabajando en el ámbito educativo un total de 26 años trabajados, mientras que el docente que menos tiempo lleva trabajado, declara que se ha dedicado a la enseñanza 5 meses. 
Como se observará a través del siguiente gráfico, el tiempo de dedicación es muy variopinto, pues abarca los periodos mínimo y máximo que hemos señalado en el párrafo anterior:

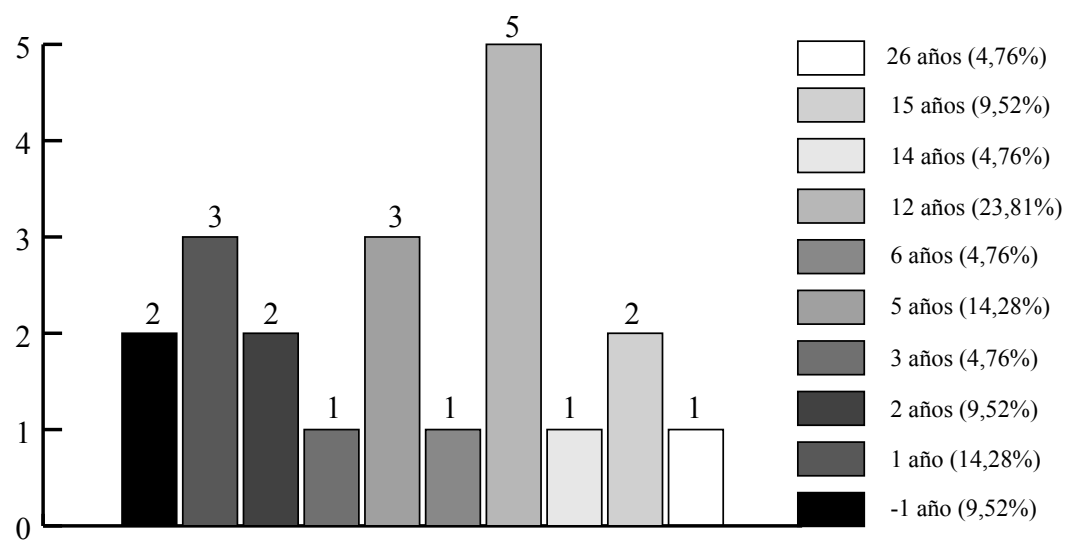

Años de dedicación a la docencia

En cuanto a la comparación de tiempo dedicado a la docencia en un centro público (tomado como referencia) y en el centro en el que se encontraban trabajando los sujetos de estudio en el momento de realizar la presente encuesta, obtenemos los siguientes resultados:

\begin{tabular}{|c|c|c|}
\hline ENCUESTADO & $\begin{array}{l}\text { Años de docencia en } \\
\text { un centro público }\end{array}$ & $\begin{array}{l}\text { Años de docencia en } \\
\text { su centro educativo }\end{array}$ \\
\hline Encuestado $\mathrm{n}^{\mathrm{o}} 1$ & 1 año & 1 año \\
\hline Encuestado $\mathrm{n}^{\circ} 2$ & 3 años & 3 años \\
\hline Encuestado $\mathrm{n}^{\circ} 3$ & 2 años & 6 años \\
\hline Encuestado $\mathrm{n}^{\circ} 4$ & 2 años & 6 años \\
\hline Encuestado $\mathrm{n}^{\circ} 5$ & 11 años & 11 años \\
\hline Encuestado $\mathrm{n}^{\circ} 6$ & 17 años & 12 años \\
\hline Encuestado $\mathrm{n}^{\circ} 7$ & 8 años & 8 años \\
\hline Encuestado $\mathrm{n}^{\circ} 8$ & 4 años & 5 años \\
\hline
\end{tabular}




\begin{tabular}{|c|c|c|}
\hline ENCUESTADO & $\begin{array}{c}\text { Años de docencia en } \\
\text { un centro público }\end{array}$ & $\begin{array}{c}\text { Años de docencia en } \\
\text { su centro educativo }\end{array}$ \\
\hline Encuestado $n^{\circ} 9$ & 2 años & 2 años \\
\hline Encuestado $\mathrm{n}^{\circ} 10$ & 0 años & 1 año \\
\hline Encuestado ${ }^{\circ} 11$ & 0 años & 1 año \\
\hline Encuestado $\mathrm{n}^{\circ} 12$ & 0 años & 1 año \\
\hline Encuestado ${ }^{\circ} 13$ & 0 años & 1 año \\
\hline 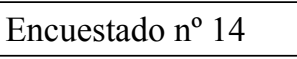 & 0 años & 2 años \\
\hline 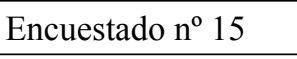 & 1 año & 0 años \\
\hline Encuestado n ${ }^{\circ} 16$ & 1 año & 0 años \\
\hline Encuestado $\mathrm{n}^{\mathrm{o}} 17$ & 2 años & 6 años \\
\hline Encuestado $\mathrm{n}^{\circ} 18$ & 1 año & 1 año \\
\hline Encuestado n ${ }^{\circ} 19$ & 25 años & 25 años \\
\hline Encuestado $\mathrm{n}^{\mathrm{o}} 20$ & 0 años & 15 años \\
\hline 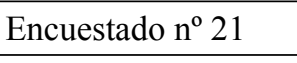 & 0 años & 15 años \\
\hline
\end{tabular}

De estos datos podemos inferir que hay una disparidad entre el tiempo trabajado en centros públicos y privados, así como en el ámbito de la experiencia docente, según se trate de un encuestado u otro. También se puede apreciar una relativa movilidad del profesorado, salvo quizá, en los casos de los encuestados 5 y 6 , así como en los tres últimos encuestados, que acusan una permanencia en el centro donde trabajan bastante prolongada.

\subsection{Nivel de estudios de los encuestados}

Al respecto del nivel de estudios de los docentes encuestados, 10 docentes poseen el título de licenciado en Filología Hispánica o equivalente, habiendo cursado 9 de ellos sus estudios en una universidad polaca (concretamente, en la Universidad Jaguelónica de Cracovia en todos los casos) y 1 persona en una universidad venezolana (la Universidad del Zulía de Maracaibo). Se ha de señalar igualmente, que 
de esos 10 docentes, 4 de ellos poseen otros estudios universitarios además de la titulación de Filología Hispánica: 2 docentes poseen un título de posgrado francopolaco y los 2 restantes poseen respectivamente la licenciatura en Biología por un lado, y la licenciatura en Teoría de la Literatura, por otro.

Asimismo apreciamos el hecho de que 3 docentes, en el apartado de la encuesta destinado a señalar si se posee la licenciatura en Filología Hispánica han marcado la casilla afirmativa, aunque a continuación, en el apartado contiguo destinado a indicar en qué universidad han obtenido dicha licenciatura, escriben que "no saben/no contestan". En este caso, además, 1 de los docentes indica que posee el Curso Pedagógico como titulación añadida, mientras que los otros 2 docentes señalan haber estudiado otra titulación más en la Universidad de Medellín (Colombia), sin indicar qué titulación ha sido la cursada. Así pues, pasamos a exponer los porcentajes correspondientes a los titulados en Filología Hispánica en el siguiente gráfico:

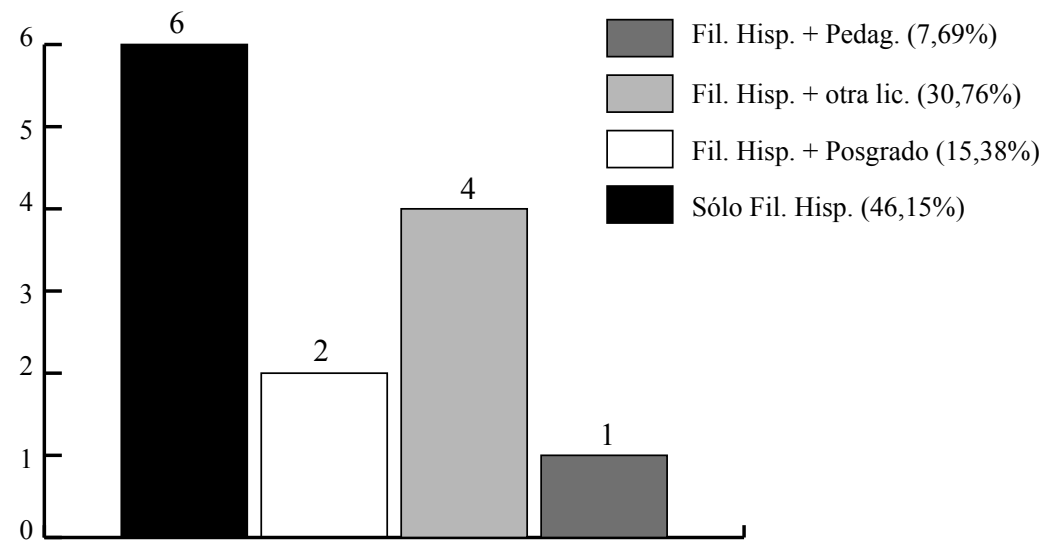

Distribución de titulados en Filología Hispánica

Por otra parte, siguiendo con el aspecto de los estudios superiores, 1 docente posee la licenciatura en Filología Románica y otro más posee la licenciatura en Filosofía y Teología, siendo en ambos casos la única titulación superior que declaran tener. A esto hay que unir el 
hecho de que nos encontramos con 2 personas que poseen la titulación de diplomado en Filología Hispánica y que también poseen la licenciatura en Filología Germánica:

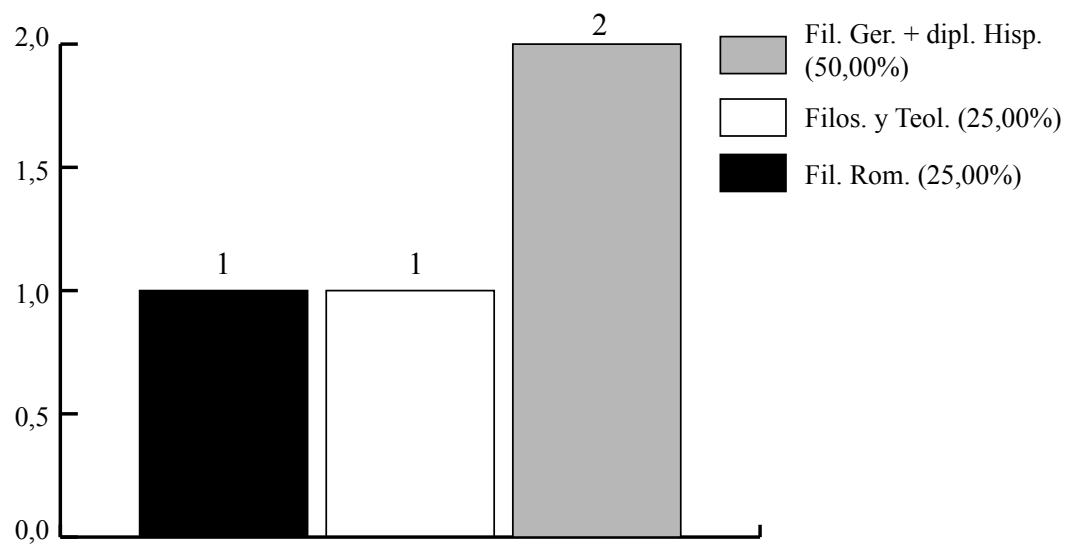

Distribución de titulados en otros estudios superiores

En cuanto a otro tipo de estudios realizados, 3 de los docentes han indicado que sólo poseen un diploma de español por parte de una academia privada de idiomas.

Prosiguiendo con el análisis dedicado al nivel de formación de los docentes encuestados, también se les ha preguntado si se hallan en posesión de algún título acreditativo de dominio de una lengua extranjera, obtenido mediante examen realizado por alguna entidad de acreditación lingüística. En este sentido, 4 docentes señalan que poseen el DELE ${ }^{9}$ superior, 1 indica que posee el DELE intermedio y 1 docente más hace constar que posee el DELE, sin aportar información acerca del nivel alcanzado. Por otra parte, 2 docentes declaran poseer un diploma en Lengua Inglesa, sin indicar qué tipo de diploma es, qué organismo o institución lo ha expedido, así como tampoco el nivel alcanzado. Todo ello lo podemos visualizar en el siguiente gráfico:

${ }^{9}$ DELE: Diploma de Español como Lengua Extranjera. 


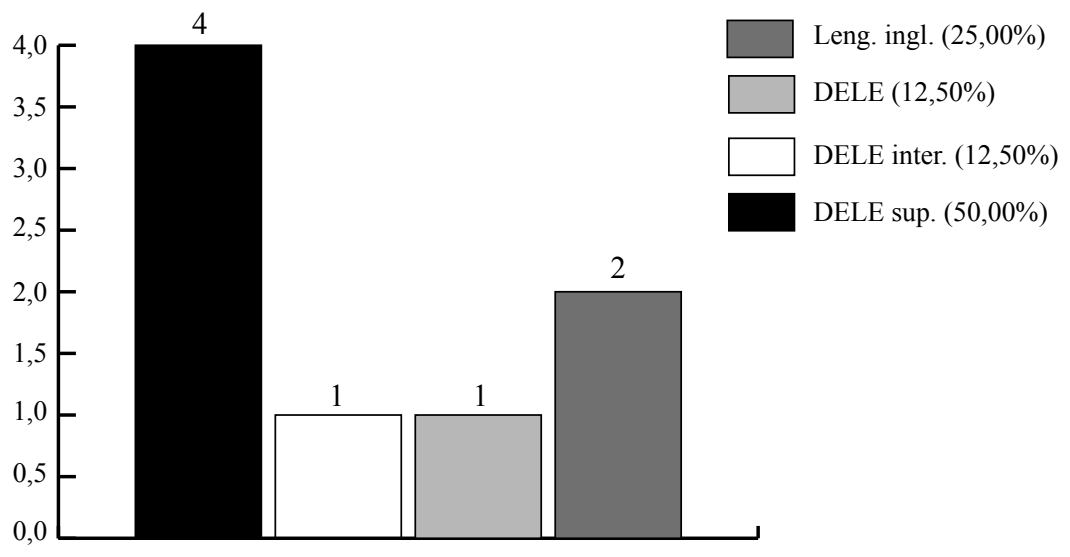

Diplomas de lenguas extranjeras obtenidos por los docentes

Resulta curioso el hecho de contrastar los datos sobre el nivel de estudios y sobre los diplomas que se poseen en lenguas extranjeras, dado que obtenemos la lectura de que los 3 docentes que habían indicado poseer únicamente un diploma de español expedido por una academia de idiomas poseen el DELE superior. Otro docente poseedor del DELE superior, asimismo es titulado en las licenciaturas de Filología Hispánica y de Biología respectivamente.

Por su parte, el docente que ha indicado hallarse en posesión del DELE sin explicitación del nivel, es a su vez, titulado en Filología Románica. Continuando con este análisis, los 2 docentes que poseen el diploma en Lengua Inglesa, son licenciados en Filología Hispánica y también poseen estudios de posgrado francopolacos.

Hemos dejado para el final el caso del único docente que declara poseer el DELE intermedio, dado que, a nuestro juicio, se trata de una situación muy peculiar, puesto que éste no indica que tenga ningún tipo de estudios, ni universitarios ni de otra índole, lo cual parece sorprendente de cara al hecho de estar enseñando en un centro de secundaria, dado que, como pudimos ver en el capítulo dedicado al desarrollo profesional del profesorado en Polonia, es obligatorio disponer del título de diplomado para ejercer en la educación secun- 
daria obligatoria y de licenciado para poder ejercer en la educación secundaria superior.

Así pues, haciendo un balance general del nivel formativo de los docentes, podemos señalar que predomina la formación de grado superior en los mismos, con algunas salvedades, tal como se ha podido leer en párrafos anteriores. Ello nos ofrece un panorama en el cual vemos que los centros educativos prefieren contratar a personas con titulación superior, cumpliendo así con la normativa polaca al respecto de quién puede ser profesor en la enseñanza secundaria [Marszałek Sejmu, 2006: 26-35], aunque se dan 4 excepciones, 2 de ellas en centros públicos y otras 2 en centros privados.

Para finalizar con este apartado, ofrecemos en el siguiente gráfico un resumen global acerca de la formación de los docentes encuestados:

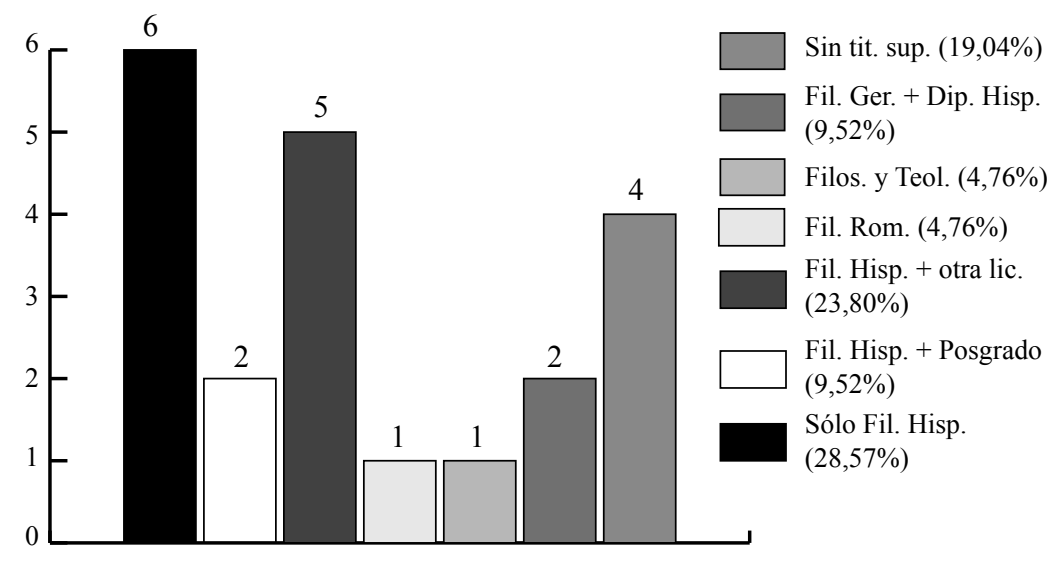

Nivel de estudios de los docentes encuestados

\subsection{Contacto con la lengua y la cultura españolas por parte de los docentes}

Un aspecto que se ha tenido en cuenta a la hora de obtener una perspectiva general sobre los docentes, es el contacto con la lengua española y por ello se ha preguntado a los mismos acerca de esta cuestión. 
De los 21 docentes encuestados, la gran mayoría (18), afirma tener o haber tenido contacto directo con la lengua española, mientras que los otros 3 , indican que no han tenido contacto con esta lengua. Así, los lugares donde se han dado estos contactos, según los datos recabados en la encuesta, han sido los siguientes: en España, 10 docentes; en Polonia, 3 docentes; en España y Cuba, 2 docentes; en Colombia, 2 docentes y hay un solo docente que no ha indicado el lugar de contacto, aunque posteriormente señalará que es hablante nativo de español. Así, el siguiente gráfico nos mostrará visualmente los porcentajes que corresponden a las respuestas dadas:
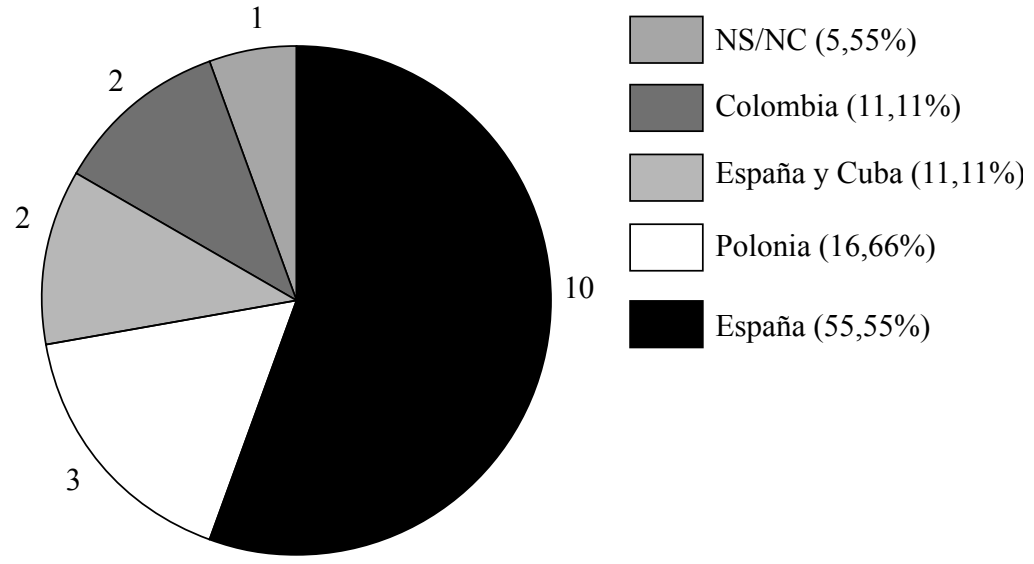

España $(55,55 \%)$

Lugares de contacto con el español

Mayoritariamente, las razones por las que se ha producido ese contacto con la lengua española han sido las laborales, señaladas por 7 encuestas, seguidas del disfrute de una beca (3 respuestas), por residencia en el país ( 2 respuestas), por realización de intercambios escolares ( 2 respuestas), por ser hablante nativo ( 2 respuestas), por realización de una estancia con el programa Erasmus (1 respuesta) y por realización de diversas estancias académicas (1 respuesta). No obstante, hemos de indicar que en una de las encuestas a las que se responde que el contacto se ha producido a través del trabajo, la acción es ubicada en Polonia y no en España u otro lugar, por lo que 
hemos de deducir que el contacto debe de darse presumiblemente con nativos hispanohablantes que también desarrollen su actividad profesional en el mismo centro de enseñanza que el docente encuestado. El siguiente gráfico nos mostrará la proporción de casuísticas en las que se ha tenido contacto con la lengua española:
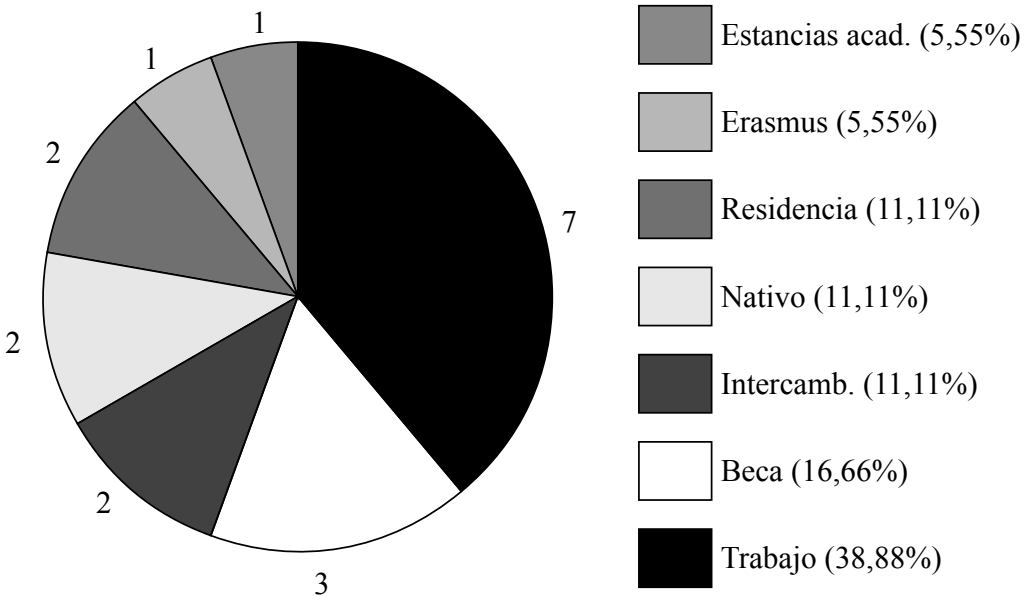

Casuísticas de contacto con el español

En último lugar, basándonos en las 18 encuestas que responden afirmativamente al hecho de tener contacto con la lengua y la cultura españolas, llama la atención, en cuanto a la duración de esos contactos, lo variopinto de las respuestas. Así, nos encontramos con el hecho de que en 2 encuestas se contesta que se ha tenido contacto durante 25 años, en otras 3 encuestas se señala que la duración del contacto ha sido de 8 meses y continuando con esta dinámica, en 1 encuesta se indica que la duración ha sido de más de un año, en otra que dicha duración ha sido de 6 meses y en otra más, se responde que el contacto se produce 2 veces al año. Eso en cuanto a los que responden con cifras más o menos concretas. En cuanto al resto de encuestas, encontramos que 2 docentes señalan "algún tiempo" como respuesta. Otros 2 docentes contestan que el contacto ha sido durante el "curso académico", mientras que otro más señala que ha sido en "numerosas 
ocasiones" y por último, un docente más ha respondido que el contacto se limita al "periodo vacacional". Para concluir, 1 encuestado señala que "no sabe o no contesta", y por supuesto, los dos hablantes nativos de español no han escrito nada en este campo de la encuesta.

\subsection{El salario del profesorado en la educación secundaria}

Este, quizá, haya sido uno de los apartados más peliagudos de la encuesta, dado que hemos podido apreciar numerosas reticencias a la hora de declarar qué salario mensual perciben los docentes en la enseñanza secundaria. De hecho, de las 21 encuestas realizadas, sólo hemos obtenido 7 respuestas, lo cual indica la existencia de una importante reserva por parte de los docentes a la hora de declarar sus ingresos. Presumiblemente, intuimos que esta reserva en cuanto a declarar los ingresos puede deberse a que las cantidades percibidas son excesivamente altas (teniendo en cuenta que el salario mínimo establecido para el año 2010 ascendía a 1317,00 PLN al mes [Prezes Rady Ministrów, 2009: 2735 (Presidencia del Consejo de Ministros) ${ }^{10}$ ]). Otra posibilidad radicaría en un factor cultural de la sociedad polaca por el que existe cierto tabú a la hora de hablar de los ingresos que se obtienen como rendimiento del trabajo, dado que precisamente en el ámbito de la educación el pluriempleo es un hecho común.

Sea como fuere, en las respuestas obtenidas en este epígrafe podemos ver cifras que van desde los 500,00 $\mathrm{PLN}^{11}$ al mes hasta los 3000,00 PLN al mes. En este caso, quizá podremos apreciar mejor la situación a través del siguiente gráfico:

${ }^{10}$ Obwieszczenie Prezesa Rady Ministrów z dnia 24 lipca 2009 r. w sprawie wysokości minimalnego wynagrodzenia za pracę w $2010 \mathrm{r}$.

11 Símbolo internacional de la moneda polaca, conocida como złoty. 


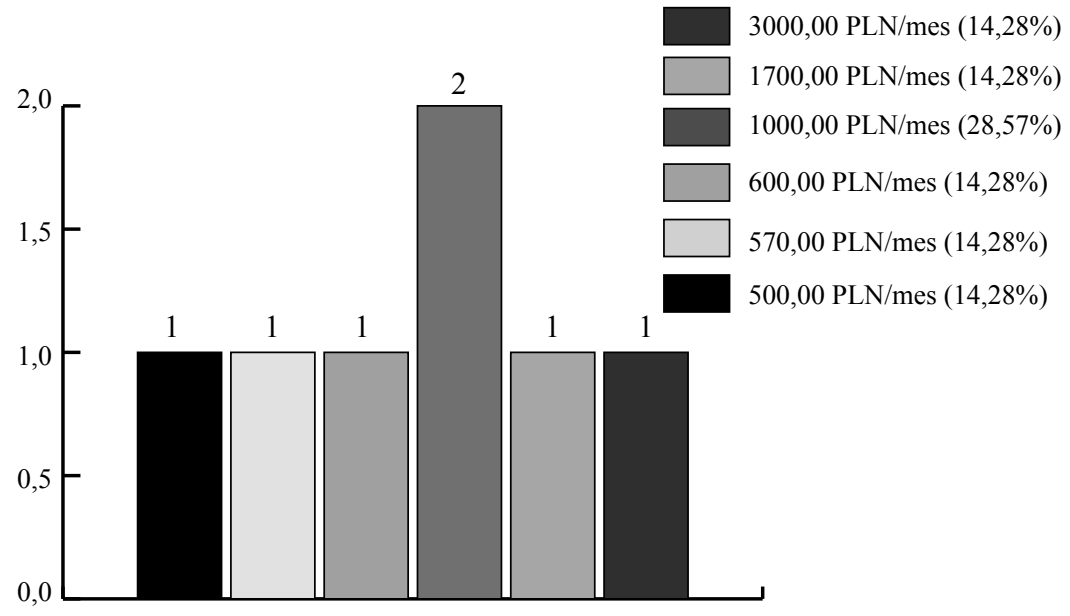

Volumen de salarios mensuales obtenidos por los docentes (en PLN)

\subsection{Niveles de satisfacción en el trabajo}

Este apartado posiblemente es el más relevante de la encuesta realizada entre los docentes de ELE del área metropolitana de Cracovia, ya que se centra en el aspecto de la valoración en el ámbito laboral. En este caso, las respuestas obtenidas han sido bastante diversas, aunque en general, el $83,33 \%$ de los encuestados (20 encuestas) valora positivamente su grado de satisfacción en el trabajo, frente a un 4,16\% (1 encuesta) que no está satisfecho.

Hay que hacer especial mención al hecho de que 3 de los encuestados $(12,50 \%)$ que han contestado afirmativamente, también han señalado que no son felices en el trabajo: 2 de ellos indican que no saben o no contestan a los porqués de su negativa, mientras que otro señala que "a veces tiene que forzar a alguien a aprender". En cuanto al único docente encuestado que contesta no saber si su trabajo le satisface, éste aduce como razón que "todo depende del grupo que se tenga". 


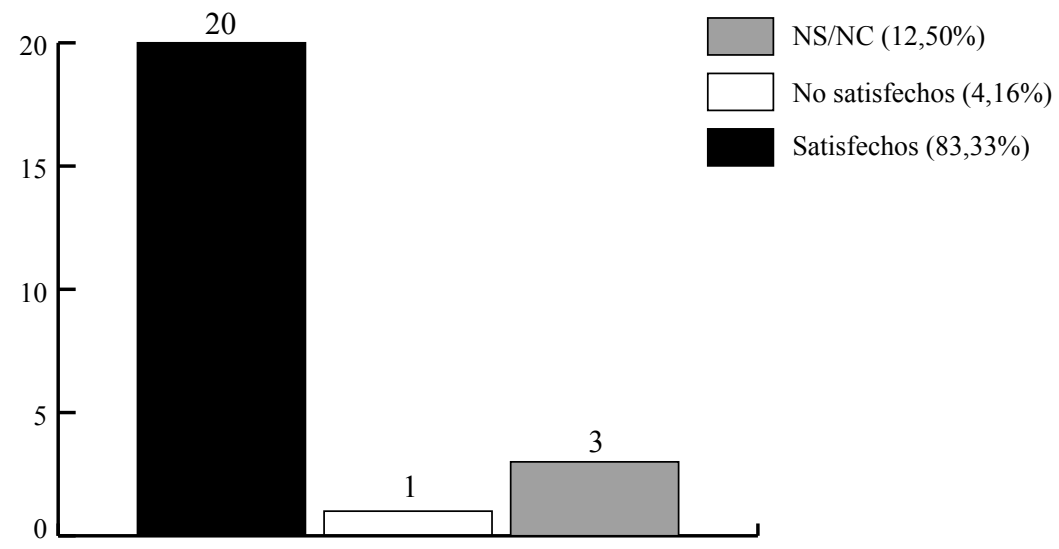

Satisfacción en el trabajo

Volviendo a aquellos que declaran estar satisfechos con su trabajo, encontramos diversas razones por las que manifiestan tal satisfacción, aunque para no extendernos mucho sobre este aspecto, abordaremos aquellas que se reiteran con mayor frecuencia. En primer lugar 6 docentes señalan que "les gusta enseñar español /LE", mientras que observamos que 4 indican que "aprecian el ambiente del centro". Además, en 2 encuestas se indica que hay un "buen contacto con los estudiantes" y en otras 2 encuestas se valora la "satisfacción que le proporciona el trabajo" al docente.

Con posterioridad hay respuestas variadas únicas que abarcan diversos elementos que inciden en las "buenas condiciones laborales", el "contacto directo con los jóvenes", la existencia de "grupos pequeños", la "posibilidad de desarrollar intereses personales", la "excelente organización académica" $\mathrm{o}$, finalmente, el "excelente nivel de educación en la mayoría de los estudiantes".

En estas opiniones detectamos que destacan dos aspectos de entre todos los indicados por los encuestados: por un lado, el grado de satisfacción profesional y por otro lado, las buenas cualidades del centro en el que los docentes desarrollan su actividad laboral. También en algunos de estos comentarios, tal como se puede observar, se hace referencia a los estudiantes y el tipo de tratamiento que éstos dispensan 
a los docentes, los cuales en general, parecen hallarse satisfechos por el mismo.

Por otra parte, en cuanto a las respuestas negativas o de indiferencia sobre la satisfacción proporcionada por el trabajo realizado, podemos apreciar, tal como se indicaba al principio de este apartado, que los profesores focalizan su descontento precisamente sobre el alumnado, no aportando ninguna información contra la satisfacción profesional ni contra las cualidades del centro docente.

\subsection{Aspectos que cambiarían los docentes en el trabajo}

Han sido de especial importancia los datos compilados en esta parte de la encuesta dado que, si bien los docentes no señalaron ningún aspecto negativo sobre el centro o sobre el sistema educativo en el apartado anterior, a través de las respuestas vertidas de aquellos elementos que cambiarían o modificarían en su trabajo podemos ver que sí existen distintas deficiencias que, en algunos casos, aparecen con mayor frecuencia y que se refieren a la organización docente del centro en el que desarrollan su actividad profesional.

Así pues, en principio hay que hacer notar que 4 encuestados señalan que "los grupos con menos alumnos" es una importante necesidad de cambio en el centro educativo. También 3 encuestados indican que son necesarias "más horas de clase", 2 encuestados plantean como problema "el número de alumnos en el grupo", otros 2 encuestados dicen que "es importante elaborar un programa (de enseñanza)", 2 encuestados más señalan la necesidad de "reformar el sistema de enseñanza en la secundaria", 2 encuestados aportan como hecho necesario la "compra de libros para los alumnos" y, por último, otros 2 más indican que las cosas que hay que cambiar son "muchas".

Frente a estas opiniones, que inciden en los problemas que se deberían abordar en los centros de trabajo y en el sistema educativo, contrastan las respuestas de 3 docentes, que afirman que en su trabajo no hay que cambiar "nada", o la de 1 docente más, que señala que sólo hay que cambiar "algunas cosas". 
Tal como se puede colegir de lo dicho, se dan muchas más respuestas en el sentido de que hay cambiar algunos elementos relacionados con el trabajo de los docentes, concretamente $17(80,95 \%)$, frente a las respuestas que señalan la ausencia de problemas en el trabajo (2 encuestas, lo que supone un 9,52\%) o sólo hay algunos problemas, sin entrar a fondo en los mismos ( 1 encuesta, que representa el 4,76\%).

\subsection{Problemas que indican los docentes en relación con el trabajo en un centro público}

No se deben dejar de lado las opiniones que tienen los docentes acerca de los problemas con el trabajo en un centro de enseñanza público, dado que constituyen un indicador de aquellos aspectos que disminuyen la valoración del docente en cuanto a su grado de satisfacción en el desarrollo de sus tareas cotidianas en el ámbito educativo. Obviamente, los aspectos que atañen a la dinámica de funcionamiento ordinaria del centro educativo a veces pueden constituir un hecho desmotivador en la función docente, dado que, como veremos a continuación, a tenor de lo indicado por los encuestados se puede apreciar que los múltiples factores problemáticos, a veces, escapan del control del profesor puesto que, bien no tiene la capacidad decisoria suficiente para poder resolverlos, bien son factores externos que no puede controlar.

En cuanto a este apartado, los encuestados han tenido la oportunidad de responder hasta en 5 ítemes distintos acerca de los problemas que encuentran en su centro, por lo cual se da un amplio abanico de respuestas, sintetizadas en la medida de lo posible, atendiendo a factores comunes en las mismas, aún cuando el enunciado literal varíe un poco de un docente a otro.

En primer lugar, se han de destacar las respuestas más repetidas por parte de los encuestados, apareciendo en 5 ocasiones la cuestión de que hay demasiados alumnos en las clases y también en otras 5 ocasiones se achaca a los alumnos la ausencia de ganas o interés hacia los idiomas extranjeros. Otro problema que se señala hasta en 3 ocasiones es el bajo número de grupos de español /LE, lo que probablemente nos lleva al primer problema planteado en estas líneas. 
Con una menor presencia, se dan cuestiones más dispersas, tales como la falta de material escolar, señalada 2 veces por los docentes o la falta de motivación por parte de los tutores y las familias de los alumnos, cuestión que también aparece 2 veces en las respuestas.

Respuestas variadas sobre otros problemas que plantean los docentes en los centros educativos y que aparecen una vez en cada caso son, por ejemplo: las pocas horas de docencia de español /LE, el exceso de burocracia en el centro, el nivel de ingresos del profesorado, las faltas de asistencia del alumnado, la dificultad de acceso a la fotocopiadora, los problemas que hay con las clases de educación especial, la falta de encuentros y charlas con las familias de los alumnos o la baja intención del alumnado en realizar el examen de reválida de español.

Además de los factores tratados, también se da el caso de que 2 docentes simplemente han declarado al respecto de este apartado que "no les concierne" el asunto y 2 más han respondido que "no hay" problemas en su centro educativo.

Por último es necesario anotar la salvedad de que el total de docentes que ha respondido a alguno de los ítemes ha sido de $15(71,42 \%)$, frente a $6(28,57 \%)$ que han declinado describir cualquier tipo de problema existente en su centro educativo. Por ello, en cuanto al volumen de respuestas, podemos apreciar en el siguiente gráfico los porcentajes al respecto de este apartado:
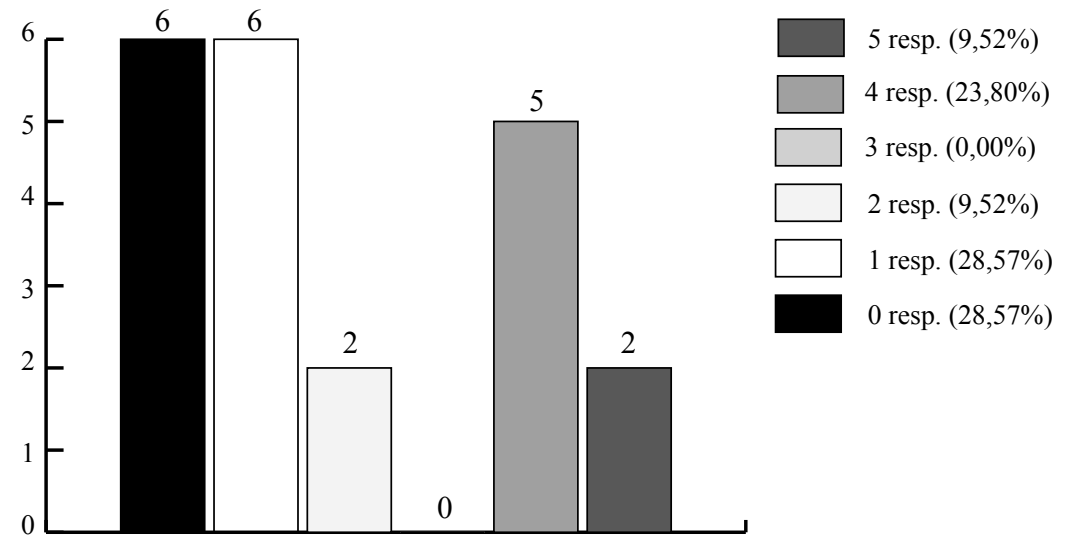

Volumen de respuestas realizadas por los encuestados 
4.8. Grado de interés de los estudiantes por el aprendizaje de español /LE

Casi finalizando la encuesta, hemos dedicado tres apartados a los estudiantes de español /LE, a fin de que los docentes ofrezcan una visión global acerca del interés, de la participación y de las motivaciones que tienen para estudiar esta lengua, dado que a pesar de que primera vista pudiera parecer que los discentes no desempeñan un papel significativo en el grado de satisfacción profesional del profesorado, a tenor de las respuestas obtenidas en epígrafes anteriores, podemos apreciar que los docentes sí que señalan al alumnado como un factor importante en el desarrollo de su función profesional, por lo que habremos de colegir que el hecho de realizar su función educadora con grupos participativos y motivados refuerza el grado de satisfacción de dichos docentes.

En estos tres apartados los encuestados han tenido la oportunidad de seleccionar más de una respuesta posible, por lo que hemos adoptado el criterio de ajustar los porcentajes en función de la cantidad de respuestas señaladas en cada ítem en lugar de calcularlos, como habíamos venido haciendo hasta el momento, en función del número de encuestas realizadas.

Así, en este apartado hemos tenido en consideración el grado de interés de los estudiantes a la hora de aprender español /LE. Al respecto de esta pregunta, 3 docentes valoran dicho interés como "muy alto" aunque 1 de ellos también señala que el interés es "alto". Precisamente sobre esa última valoración de interés, la mayoría de los docentes (15), valoran el interés de los estudiantes como "alto". Por su parte, hay 6 respuestas que indican un interés "medio", aunque 2 de las encuestas en las que se indica este grado de interés de los estudiantes también señalan que el grado de interés es "alto".

Lo destacable de estas valoraciones es que ninguno de los encuestados ha señalado que el grado de interés de los estudiantes sea "bajo" o "sin interés". Así pues, la situación se resume en el siguiente gráfico de esta manera: 


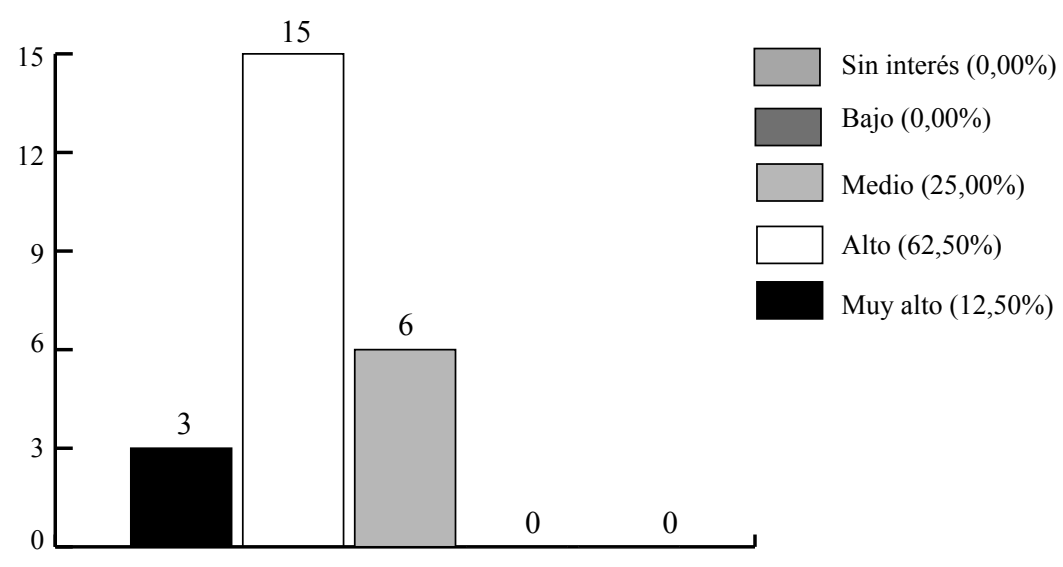

Grado de interés de los estudiantes por el español /LE

\subsection{Participación de los estudiantes en las clases de español /LE}

Acerca de la valoración que hacen los encuestados acerca del grado de participación de los estudiantes en las clases de español /LE, los docentes responden mayoritariamente que sí participan (14 respuestas), aunque de cerca le sigue la cantidad de docentes que señalan que "depende" (10 respuestas). Se ha de mencionar el hecho de que en este caso, al igual que en el anterior apartado, hay 3 docentes que responden en ambos ítemes. Lo más destacable de esta parte de la encuesta es que ninguno ha respondido negativamente. Así, la situación queda reflejada en un gráfico de la siguiente manera: 


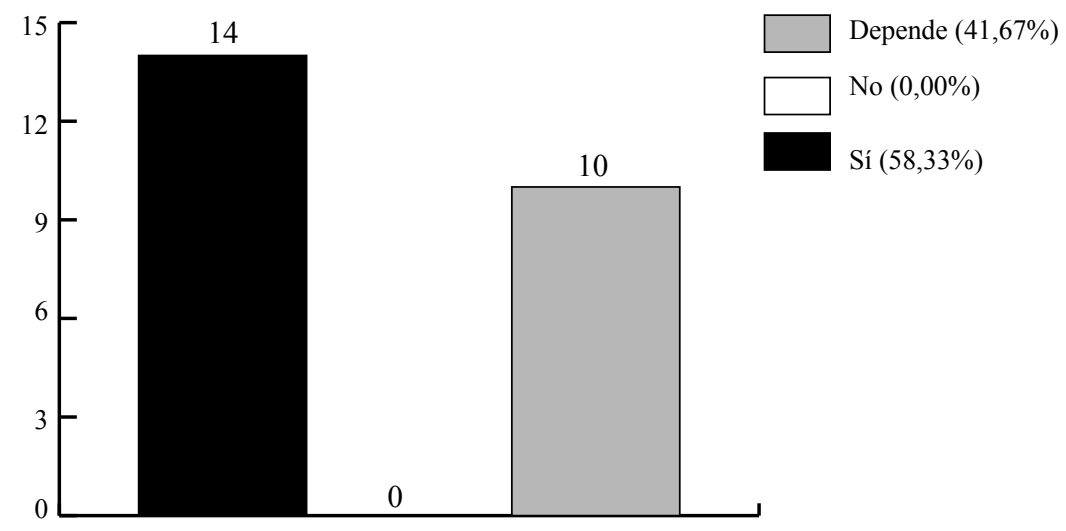

Participación de los estudiantes en las clases de español/LE

\subsection{Motivaciones de los estudiantes para aprender español /LE}

Para finalizar con el tratamiento y valoración de las encuestas, el último apartado al que han tenido que contestar los encuestados hacía referencia a las diversas motivaciones que tienen los estudiantes para aprender español /LE, habiéndose dado múltiples variables en las respuestas de los docentes que, en algunos casos, han elegido varios ítemes, por lo que ajustaremos, al igual que en las dos ocasiones anteriores, los porcentajes al número total de respuestas y no al número de encuestas realizadas.

Pasando al análisis de esta cuestión, nos encontramos con que 12 docentes señalan que el interés de los estudiantes por aprender español /LE se relaciona con la realización de las pruebas de reválida (matura), mientras que todos ellos (21) achacan a la moda del español ese interés por el aprendizaje de esta lengua. En cuanto a la realización de viajes a un país hispanohablante como motivo de interés, son 11 los docentes que lo señalan, pero sólo 5 docentes consideran que dicho interés viene dado por las perspectivas de trabajo en un país hispanohablante. Para ir finalizando, 8 docentes indican que la motivación para aprender español /LE puede deberse a la planificación 
futura de la realización estudios superiores relacionados con esta lengua y sólo 3 docentes marcan el ítem "otros" como motivación para elegir el estudio del español /LE.

Como hemos dicho con anterioridad, en este apartado las posibilidades de respuesta eran múltiples, aunque queremos destacar el hecho de que sólo 2 profesores han marcado como respuesta todos los ítemes $\mathrm{y}$, a su vez, 4 profesores han marcado como única respuesta el ítem que hacía referencia a la moda del español. Así pues, en los dos gráficos que presentamos a continuación podremos ver, por un lado, la proporción de respuestas del profesorado en cuanto a los motivos de los estudiantes para estudiar el español/LE y, por otro lado, el volumen de respuestas escogidas por los docentes que han realizado la encuesta:
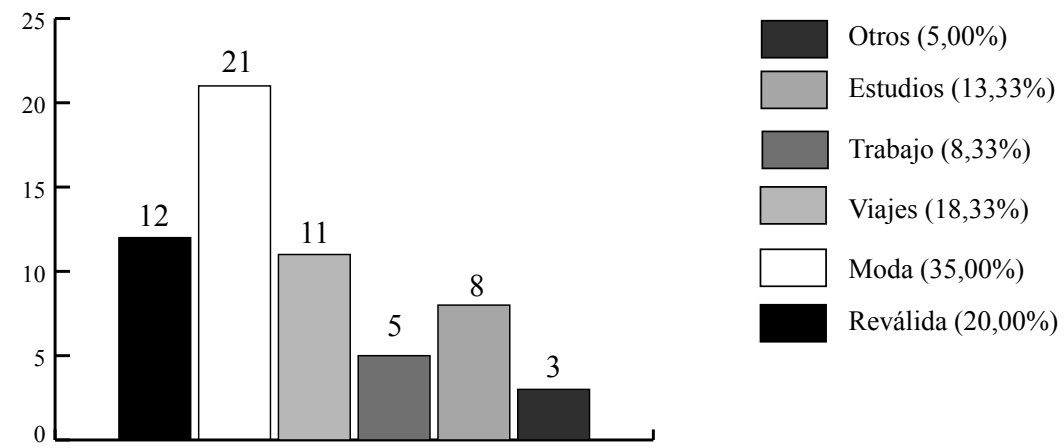

Motivaciones de los estudiantes para cursar español /LE
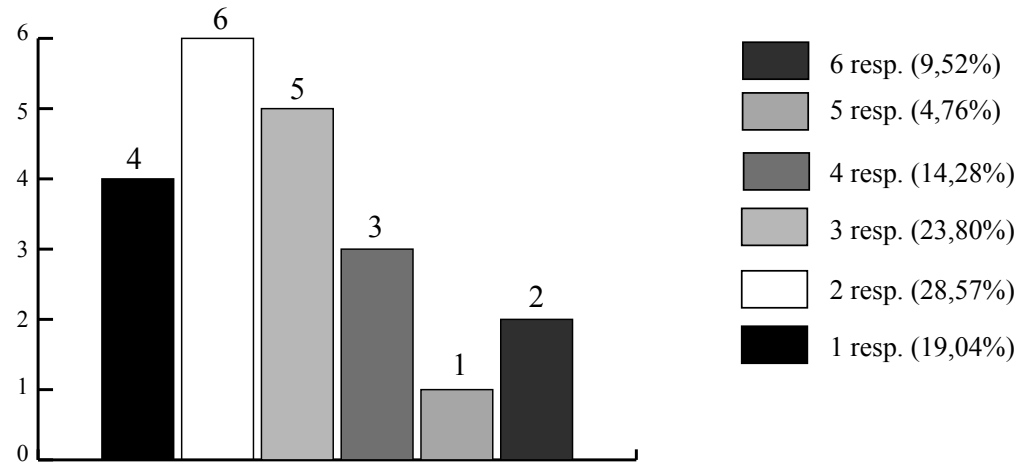

Cantidad de respuestas múltiples escogidas por los encuestados 


\section{Conclusiones}

En primer lugar, hemos de reiterar el hecho de que la mayoría de los docentes sean mujeres (16 de 21) y que además, de todos los docentes encuestados, los 3 que declaran no poseer estudios superiores (sólo indican que han cursado español en una academia de idiomas o que poseen el DELE) sean hombres. Esto nos podría ofrecer una lectura que tendría su parangón en el número de personas por género que escogen realizar estudios universitarios humanísticos, dado que si atendemos a la experiencia personal universitaria del autor de este artículo, es predominantemente mayor el número de mujeres frente al de hombres que cursan la titulación de Filología Hispánica y otras titulaciones afines. Parece lógico inferir que la proporcionalidad señalada en los estudios universitarios tiene un reflejo en el ámbito laboral que hemos analizado.

En cuanto al tiempo que los encuestados llevan impartiendo docencia, hemos podido ver que, si bien la media total se encuentra en los 7,6 años, encontramos una divergencia notable en algunas encuestas en cuanto al tiempo trabajado en un centro público y en el centro educativo donde los docentes prestaban sus servicios en el momento en el que cumplimentaron las encuestas, lo cual se puede ver en las encuestas número 3, 4 y 17, donde los encuestados declaran haber trabajado 2 años en un centro público, mientras que señalan que llevan trabajando en su centro 6 años. Esta desviación se debe al hecho de que el centro en el que trabajan es privado, por lo que la experiencia que pueden aportar en centros públicos es notablemente inferior al tiempo que llevan trabajando en el centro educativo donde prestaban sus servicios en el momento de realizarse esta investigación.

Mención aparte merece la cuestión del salario del profesorado, dadas las reticencias que hemos encontrado a la hora de contestar a esta pregunta por parte de los encuestados. Como expusimos en las valoraciones de las encuestas, sólo 7 docentes han respondido, facilitándonos una horquilla que va de los 500,00 PLN mensuales a los 3000,00 PLN mensuales, suponiendo una media total, en función 
a las cantidades indicadas, de 1195,71 PLN al mes. Hemos de tener en cuenta que es significativo el hecho de que 14 encuestados se hayan negado a declarar sus ingresos mensuales, dado que entendemos que el salario es un factor de análisis de la satisfacción de un profesional, por lo que podríamos deducir que puede existir un reparo en indicar la cuantía percibida por el trabajo docente, pues las cantidades obtenidas no resultan satisfactorias para el profesorado y por eso no las señalan en la encuesta.

Importante aspecto es la pregunta que se les hace directamente en cuanto a su grado de satisfacción en el trabajo, dato importantísimo para esta encuesta, dado que es uno de los elementos que nos habíamos propuesto analizar a la hora de afrontar este trabajo. Así, podemos ver en el capítulo dedicado a la valoración de las respuestas obtenidas, que la gran mayoría de los encuestados (en este caso, 20 de ellos) se declara satisfecho con su trabajo, mientras que sólo 1 encuestado ha respondido que no está satisfecho con su trabajo. Curiosamente, se ha dado el caso de que 3 encuestados de los 20 que han respondido favorablemente a esta cuestión, también han marcado la casilla de "no sabe/no contesta", por lo que nos ha obligado a replantear los porcentajes en función al total de respuestas y no de encuestas, correspondiendo el $83,33 \%$ a respuestas afirmativas, el $4,16 \%$ a la respuesta negativa y el $12,50 \%$ a las respuestas de "no sabe, no contesta".

Las dos cuestiones analizadas con posterioridad, es decir, aquellos aspectos que los docentes cambiarían en su trabajo y los problemas que éstos señalan en relación con su centro de trabajo también tienen una especial relevancia en este análisis, dado que reflejan la percepción que los encuestados tienen de su entorno laboral y del desarrollo de su propio trabajo.

Así, en cuanto a los aspectos que los docentes cambiarían en su trabajo, parece que bastantes de ellos (en este caso 11) se centran más en aspectos relacionados con la organización docente, tal como hemos visto en el análisis realizado en el apartado 4.6., mientras que 2 encuestados hacen referencia a problemas en el propio sistema educativo, y 2 más, como ya vimos con anterioridad, señalan que las 
cosas que hay que cambiar son "muchas". Del total de encuestados, 3 indican que no hay problemas en su centro educativo o que sólo hay que cambiar alguna cosa, sin entrar en especificaciones. En general, por el tenor de las respuestas obtenidas, parece que, salvo en el caso concreto de 2 docentes, el resto del profesorado tiene una apreciación, bien positiva, bien no excesivamente negativa del lugar en el que trabajan. Especialmente se dan las respuestas más positivas, en las que se refleja la ausencia de problemas, entre los trabajadores de los centros de enseñanza privados.

Al respecto de los problemas a los que hacen referencia los docentes en relación con el trabajo desarrollado en un centro público, hemos encontrado respuestas variopintas, aunque se centran de nuevo en problemáticas que tienen que ver con la organización escolar, destacándose el ingente número de alumnos en los grupos de español /LE (5 encuestas) o el bajo número de grupos de español/LE en relación con la demanda de esta lengua por parte del alumnado (3 encuestas). Precisamente sobre el alumnado, 5 encuestas señalan que este colectivo presenta una falta de interés notable frente al aprendizaje de lenguas extranjeras, lo cual puede ser un elemento de desmotivación en el profesorado, dado que no ve su trabajo valorado positivamente por los inmediatos receptores del mismo. 2 encuestas asimismo, resaltan que existe una falta de motivación en los tutores y familiares de los alumnos, lo cual puede suponer que el profesor, a la hora de intervenir en el desarrollo formativo de dichos alumnos, se vea frustrado por la falta de apoyo externa que todo proceso educativo requiere.

Es curioso que encontremos entre otras respuestas de las que se dan en este apartado una referencia directa a los bajos salarios como elemento problemático, si bien los encuestados no habían querido manifestar en su mayoría los ingresos percibidos, tal como pudimos apreciar con anterioridad. También se incide en el hecho de que hace falta acceso a más material (bibliográfico o reprográfico) y una mayor implicación de las familias en el ámbito educativo. Por último, se ha de indicar que sólo 2 docentes explicitan que no hay ningún tipo de problema en su trabajo cotidiano. 
En último lugar, nos referiremos a las valoraciones que hace el profesorado sobre los alumnos que están a su cargo. En general, destacan que el interés del alumnado por el aprendizaje del español / LE es alto (15 encuestados), mientras que 6 encuestados señalan que el interés es medio. Estas cifras bien pueden correlacionarse con los datos que hemos expuesto en los párrafos anteriores que hacían referencia al desinterés por parte de este colectivo en relación con el aprendizaje de lenguas (5 encuestas).

En cuanto a la participación de los alumnos en las clases de español /LE, la mayoría (14 encuestas) señala que sí se participa en las mismas, mientras que encontramos en 10 encuestas que se indica que depende de las circunstancias. Obviamente algunos docentes han señalado ambas casillas en la encuesta tal como dijimos en el apartado correspondiente, aunque lo realmente destacable es que nadie ha marcado que no participan los alumnos en las clases, lo cual parece que sí aporta un factor positivo de la función docente que realizan estos profesionales y que el impacto de su trabajo redunda positivamente en la participación del alumnado a su cargo.

La última cuestión hacía referencia a las motivaciones de los estudiantes para elegir español /LE como asignatura. Como hemos podido ver en el análisis de los resultados, las respuestas han sido muy variadas y en muchos casos incidían especialmente en el aspecto de la moda del idioma (21 respuestas), académico (20 respuestas) o lúdico (11 respuestas). Sólo 5 de las respuestas relacionaban el factor de elección de esta lengua con el trabajo.

Por todo lo dicho, si bien existen algunos factores que causan desazón, valoraciones negativas e incluso desmotivación en el profesorado, lo que mayormente tiene que ver con la organización escolar y con el sistema educativo, también podemos apreciar que se recogen aspectos positivos en cuanto al trabajo de dicho profesorado, centrándose más estos aspectos en la propia satisfacción de ser docente $\mathrm{y}$ en el contacto directo con el alumnado. Si a este último hecho añadimos que, en la mayoría de los casos, los encuestados han valorado positivamente su propio grado de satisfacción laboral, así como la actividad del alumnado en relación con su participación en el aula, 
podemos deducir que la satisfacción nace del trato con las personas y no del sistema en el que desempeñan sus funciones docentes.

La pretensión de este artículo ha sido ofrecer una aproximación empírica que valorara las expectativas y la satisfacción profesional de los docentes del área metropolitana de Cracovia. Creemos que, en cuanto a la satisfacción profesional ya hemos indicado por dónde discurren las líneas más importantes en el párrafo anterior. En cuanto a las expectativas, parece que se hace patente una simplificación de las funciones burocrático-administrativas que tienen que realizar en sus centros de enseñanza, una mejor adecuación infraestructural a la realidad de la demanda del español /LE como asignatura por parte del alumnado y una mejora en las retribuciones salariales. El tiempo dirá si se han ido planteando las mejoras demandadas.

Por último, este trabajo bien puede dar paso a posteriores estudios que aborden los aspectos tratados en el mismo en sucesivos cortes sincrónicos, a fin de poder estudiar cuál es la evolución que se habrá de ir produciendo en este colectivo profesional. Con esta idea, concluimos el artículo, dejando la puerta abierta a nuevas investigaciones que contribuyan a desarrollar este aspecto de la evaluación externa de la calidad docente. 
Anexo I. Encuesta realizada a los docentes para analizar su grado de satisfacción con el trabajo desarrollado

\section{NAUCZANIE JĘZYKA HISZPAŃSKIEGO W SZKOLACH PUBLICZNYCH NA TERENIE KRAKOWA mgr R. Sergio Balches Arenas Uniwersytet Jagielloński w Krakowie}

Imię i nazwisko wypełniającego ankietę:

Szkoła:

Od ilu lat naucza się w placówce języka hiszpańskiego?

Jakie ma Pan/Pani wykształcenie zawodowe?

$\square$ dyplom magistra filologii hiszpańskiej (proszę podać nazwę uczelni)

$\square$ dyplom licencjata filologii hiszpańskiej (proszę podać nazwę uczelni)

$\square$ certyfikat językowy (proszę podać jaki)

$\square$ inne (proszę podać jakie)

Czy miał/a Pan/Pani bezpośredni kontakt z językiem i kulturą hiszpańską?

$\square$ nie

$\square$ tak (proszę podać gdzie, w jakich okolicznościach i jak długo) 
Od ilu lat uczy Pan/Pani języka hiszpańskiego?

w szkole publicznej?

w szkole, w której pracuje Pan/Pani obecnie?

lat

Jakie są Pana/Pani zarobki?

zł/miesiąc

Czy jest Pan/Pani zadowolony/a ze swojej pracy?

$\square$ tak (dlaczego?)

$\square$ nie (dlaczego?)

$\square$ mam mieszane uczucia (dlaczego?)

Co zmieniłby/zmieniłaby Pan/Pani w swojej pracy?

Proszę wymienić 5 głównych problemów, jakie napotyka Pan/Pani, pracując w szkole państwowej.

a)

b)

c)

d)

e) 
Situación de los docentes de español...

Jakie jest zainteresowanie Pana/Pani uczniów językiem hiszpańskim?

$\square$ bardzo duże

$\square$ duże

$\square$ średnie

$\square$ niewielkie

$\square$ brak zainteresowania

Czy uczniowie aktywnie uczestniczą w lekcjach?

$\square$ tak

$\square$ nie

$\square$ zależy

Co, Pana/Pani zdaniem, motywuje uczniów do nauki języka hiszpańskiego?

$\square$ matura / inne egzaminy

$\square$ moda na hiszpański

$\square$ podróże

$\square$ chęć podjęcia pracy w kraju hiszpańskojęzycznym

$\square$ chęć podjęcia studiów związanych z językiem hiszpańskim

$\square$ inne (jakie?) 


\section{Bibliografía}

CANO, E. (1998), Evaluación de la calidad educativa, Editorial la muralla, S.A., Madrid.

EURYDICE, "European Encyclopedia on National Educations Systems", [online] https://webgate.ec.europa.eu/fpfis/mwikis/eurydice/index.php/ Polska:Wprowadzenie - 4.04.2013.

JUNG-MIKLASZEWSKA, J., "System Edukacji w Rzeczypospolitej Polskiej. Szkoły i dyplomy", [on-line] http://www.buwiwm.edu.pl/publ/ system - 24.03.2013

MARSZAŁEK SEJMU (2006), Obwieszczenie Marszatka Sejmu Rzeczypospolitej Polskiej z dnia 17 maja 2006 r. w sprawie ogloszenia jednolitego tekstu ustawy - Karta Nauczyciela, Dz.U. z 2006 r. Nr 97, poz. 674, pp. 1-72.

MECD y Universidad de Valencia, "El mundo estudia español 2009-2010",[on-line]http://www.mecd.gob.es/dctm/redele/Material-RedEle/ el-mundo-estudia-espanol/texto-completo2009OK.pdf?documentId= 0901e72b80f3b8a5 - 4.04.2013.

MEN (1998), Ustawa z dnia 25 lipca 1998 r. o zmianie ustawy o systemie oświaty, Dz.U. z 1998 r. Nr 117, poz. 759, pp. 4320-4328.

MEN (2004), Rozporzadzenie Ministra Edukacji Narodowej z dnia 1 grudnia 2004 r. w sprawie uzyskiwania stopni awansu zawodowego przez nauczycieli, Dz.U. z 2004 r., Nr 260, poz. 2593, pp. 18339-18353.

MEN (2007), Rozporzadzenie Ministra Edukacji Narodowej z dnia 14 listopada 2007 r. zmieniajace rozporzadzenie $w$ sprawie uzyskiwania stopni awansu zawodowego przez nauczycieli, Dz.U. z 2007 r. Nr 214, poz. 1580, pp. 15484-15492.

MEN, PISA - Wyniki Badania 2009 w Polsce, [on-line] http://www.ifispan. waw.pl/pliki/pisa_2009.pdf - 4.04.2013.

OECD (2011), "The Impact of the 1999 Education Reform in Poland", OECD Education Working Papers, 49, OECD Publishing.

PREZES RADY MINISTRÓW (2009), Obwieszczenie Prezesa Rady Ministrów z dnia 24 lipca 2009 r. w sprawie wysokości minimalnego wynagrodzenia za pracęw 2010 r., Monitor Polski Nr 48, poz. 709, pp. 2735.

UNESCO (2011), International Standard Classification of Education 2011, General Conference UNESCO, Paris.

WIKIPEDIA, "PISA (badanie)", [on-line] http://pl.wikipedia.org/wiki/ PISA_\%28badanie\%29-9.04.2013. 